\title{
Sustainable Cooperation in Global Climate Policy: Specific Formulas and Emission Targets
}

\section{Citation}

Bosetti, Valentina, and Jeffrey A. Frankel. 2012. Sustainable Cooperation in Global Climate Policy: Specific Formulas and Emission Targets. HKS Faculty Research Working Paper Series RWP12-012, John F. Kennedy School of Government, Harvard University.

\section{Published Version}

http://web.hks.harvard.edu/publications/citation.aspx?Publd=8332

\section{Permanent link}

http://nrs.harvard.edu/urn-3:HUL.InstRepos:8694933

\section{Terms of Use}

This article was downloaded from Harvard University's DASH repository, and is made available under the terms and conditions applicable to Other Posted Material, as set forth at http:// nrs.harvard.edu/urn-3:HUL.InstRepos:dash.current.terms-of-use\#LAA

\section{Share Your Story}

The Harvard community has made this article openly available.

Please share how this access benefits you. Submit a story.

Accessibility 


\section{Sustainable Cooperation in} Global Climate Policy: Specific Formulas and Emission Targets Faculty Research Working Paper Series

\section{Valentina Bosetti}

Fondazione Eni Enrico Mattei

Jeffrey A. Frankel

Harvard Kennedy School and NBER

\section{April 2012 RWP12-012}

The views expressed in the HKS Faculty Research Working Paper Series are those of the author(s) and do not necessarily reflect those of the John F. Kennedy School of Government or of Harvard University. Faculty Research Working Papers have not undergone formal review and approval. Such papers are included in this series to elicit feedback and to encourage debate on important public policy challenges. Copyright belongs to the author(s). Papers may be downloaded for personal use only. 


\title{
Sustainable Cooperation in Global Climate Policy: Specific Formulas and Emission Targets
}

\author{
Valentina Bosetti and Jeffrey Frankel
}

\begin{abstract}
Valentina Bosetti, is senior researcher at Fondazione Eni Enrico Mattei, Milan, valentina.bosetti@feem.it. Jeffrey Frankel is James W. Harpel Professor of Capital Formation and Growth at the Kennedy School of Government, Harvard University, USA, Jeffrey_Frankel@harvard.edu.
\end{abstract}

\begin{abstract}
$\underline{\text { Abstract }}$
We explore a framework that could be used to assign quantitative allocations of emissions of greenhouse gases (GHGs), across all countries, one budget period at a time, as envisioned at the December 2011 negotiations in Durban. Under the two-part plan: (i) China, India, and other developing countries accept targets at Business as Usual (BAU) in the coming budget period, the same period in which the US first agrees to cuts below BAU; and (ii) all countries are asked in the future to make further cuts in accordance with a common numerical formula to all. The formula is expressed as the sum of a Progressive Reductions Factor, a Latecomer Catch-up Factor, and a Gradual Equalization Factor. This paper builds on our previous work in many ways. First we update targets to reflect pledges made by governments after the Copenhagen Accord of December 2009 and confirmed at the Cancun meeting of December 2010. Second, the WITCH model, which we use to project economic and environmental effects of any given set of emission targets, has been refined and updated to reflect economic and technological developments. We include the possibility of emissions reduction from bio energy (BE), carbon capture and storage (CCS), and avoided deforestation and forest degradation (REDD+) which is an important component of pledges in several developing countries. Third, we use a Nash criterion for evaluating whether a country's costs are too high to sustain cooperation.
\end{abstract}

JEL classification number: Q54

Keywords: Cancun, climate, concentrations, cooperation, Copenhagen, costs, developing countries, development, Duban, emissions, equity, global climate, global warming, greenhouse gas, human development, international, Kyoto, sustainable, treaty, United Nations, WITCH.

The authors would like to thank Cynthia Mei Balloch for research assistance and Subhra Bhattacharjee and Francisco Rodriguez for comments. A version of this paper appeared as Human Development Research Paper 2011/01, November 2011. The HDRP Series is a medium for sharing recent research commissioned to inform the global Human Development Report, which is published annually. In addition, Bosetti received support from the Climate Impacts and Policy Division of the EuroMediterranean Center on Climate Change. and Frankel received funding from the Sustainability Science Program which was then housed in the Center for International Development at Harvard University, supported by Italy's Ministry for Environment, Land and Sea. The views expressed herein are those of the authors and do not necessarily reflect the views of the UNDP, or any other organization. 


\section{Summary}

In December 2011, the UNFCC Conference of Parties in Durban, South Africa, chose 2015 as the deadline for negotiating a successor agreement to the Kyoto Protocol on Global Climate Change. Crucially, major developing countries agreed for the first time to the principle of adopting the same sort of legally binding emission limits as advanced countries, to take effect in 2020 .

This study explores a possible agreement in the form of a framework of formulas that produce precise numerical targets for emissions of carbon dioxide $\left(\mathrm{CO}_{2}\right)$ and other greenhouse gases, in all regions of the world in all decades of this century. The formulas are based on pragmatic judgments about what kind of cooperation is sustainable. The reason for this approach is the authors' belief that many of the usual science-based, ethics-based, and economics-based paths are not viable in practice. Successor governments will not be able politically to abide by the commitments that today's leaders make if those commitments become excessively costly relative to a strategy of dropping out.

If unraveling in a future decade is foreseeable at the time that long-run commitments are made, then those commitments will not be credible from the start. Firms, consumers, and researchers base their current decisions to invest in plant and equipment, consumer durables, or new technological possibilities on the expected future price of carbon: If government commitments are not credible from the start, then they will not raise the expected future carbon price.

Three political constraints seem inescapable if key countries are to join a new treaty and abide subsequently by their commitments: (1) Developing countries are not asked to bear any cost in the early years. (2) Thereafter, they are not asked to make any sacrifice that is different in kind or degree from what was made by those countries that went before them, with due allowance for differences 
in incomes. (3) No country is asked to accept an ex ante target that costs it more than $Y \%$ of income in present discounted value (PDV), or more than $X \%$ of income in any single budget period. The logic is that no country will agree to ex ante targets that have very high costs, nor abide by them ex post. We begin with thresholds of $X=5.0$ and $Y=1.0$.

The proposed targets for emissions are formulated assuming the following framework. Between now and 2050, the European Union follows the path laid out in the 2008 European Commission Directive; the United States and other advanced countries follow the paths specified in their submissions under the Copenhagen Accord as recorded by the time of the Cancun Summit of December 2010; while China, India and other developing countries agree immediately to quantitative emission targets, which in the first decades merely copy their business-as-usual (BAU) paths, thereby precluding leakage. These countries are not initially expected to commit to emission targets below their BAU trajectory.

When the time comes for developing countries to join mitigation efforts their emission targets are determined using a formula that incorporates three elements: a Progressive Reductions Factor, a Latecomer Catch-up Factor, and a Gradual Equalization Factor. These three factors are designed to persuade the joining countries that they are only being asked to do what is fair in light of actions already taken by others, to follow in the footsteps of those who have gone before. In the first years that a country's emission target is to decline below the BAU path, the Progressive Reductions Factor dominates. The reductions asked of lower income countries are proportionately lower. As time passes, the Latecomer Catch-up Factor becomes more important. Countries are increasingly pulled further from their BAU path and closer toward what their emissions were at the end of the $20^{\text {th }}$ century. In the latter part of the $21^{\text {st }}$ century, the formula that determines the emissions path is increasingly dominated by the Gradual Equalization Factor. National targets gradually converge in per capita terms. The 
glue that holds the agreement together is that every country has reason to feel that it is only doing its fair share.

We use the WITCH model to analyze the results of this approach in terms of projected paths for emissions targets, permit trading, the price of carbon, lost income, and environmental effects. Overall economic costs, discounted at 5 percent, average 0.6 percent of Gross World Product. The largest discounted economic loss suffered by any country from the agreement overall is 1.0 percent of income. The largest loss suffered by any country in any one period is less than 5.0 percent of income. Atmospheric $\mathrm{CO}_{2}$ concentrations level off at 500 parts per million (ppm) in the latter part of the century. We also see if it is possible to attain more ambitious environmental goals by choosing more aggressive parameters for the formulas. We manage to cap $\mathrm{CO} 2$ concentrations below 450 ppm -- delivering a predicted temperature increase of about $2.3^{\circ} \mathrm{C}$ in 2100 , not too far above the widely desired $2^{\circ} \mathrm{C}$-- but only by means of an approximate doubling of economic costs.

We do not take a position on what level of concentrations is low enough or what level of economic costs is too high. Our claim is that, whatever the environmental goal, the chances that cooperation to achieve it will be sustainable are higher if all countries join an agreement and if it is credible that they will continue to comply. These conditions, in turn, are more likely if each is given reason to feel it is being asked to do no more than its fair share, taking due account of differences in income, and if no country has to absorb an unusually large economic loss in any given period. 


\section{Introduction}

Of all the obstacles that have impeded a global cooperative agreement to address the problem of Global Climate Change, perhaps the greatest has been the gulf between the advanced countries on the one hand, especially the United States, and the developing countries on the other hand, especially China and India. As long ago as the “differentiated responsibilities" language of the Berlin Mandate of 1995 under the United Nations Framework Convention on Climate Change (UNFCCC), it was understood that developing countries would not be asked to commit legally to emissions reductions in the same time span that industrialized countries did. But as long ago as the Byrd-Hagel Resolution of 1997, it was understood that the U.S. Senate would not ratify any treaty that did not ask developing countries to take on meaningful commitments at the same time as the industrialized countries. Sure enough, the United States did not ratify the Kyoto Protocol that was negotiated later the same year. ${ }^{1}$

Each side has a valid point to make. On the one hand, the U.S. reasoning is clear: it will not impose quantitative limits on its own GHG emissions if it fears that emissions from China, India, and other developing countries will continue to grow unabated. Why, it asks, should American firms bear the economic cost of cutting emissions, if energyintensive activities such as aluminum smelters and steel mills would just migrate to countries that have no caps and therefore have cheaper energy - the problem known as leakage - and global emissions would continue their rapid rise? On the other hand, the leaders of India and China are just as clear: they are unalterably opposed to cutting

\footnotetext{
${ }^{1}$ Nor did Australia. Canada ratified, but eventually dropped out, faced with the extremely high economic cost it would have taken to achieve its emissions target. The EU is expected to have met its target.
} 
emissions until after the United States and other rich countries have gone first. After all, the industrialized countries created the problem of global climate change, while developing countries are responsible for only about 20 percent of the $\mathrm{CO}_{2}$ that has accumulated in the atmosphere from industrial activity over the past 150 years. Limiting emissions, they argue, would hinder the efforts of poor countries at economic development. As India points out, Americans emit more than ten times as much carbon dioxide per person as it does.

In December 2011, the UNFCC Conference of Parties in Durban, South Africa, produced a new ray of hope for an agreement. It chose 2015 as the deadline for negotiating a successor to the Kyoto Protocol to come into force by 2010. Crucially, major developing countries agreed for the first time to the principle of legally binding emission limits.

What is needed is a specific framework for setting the actual emission targets that signers of a Kyoto-successor treaty can realistically be expected to adopt. ${ }^{2}$ There is one practical solution to the apparently irreconcilable differences between the US and the developing countries regarding binding quantitative targets. The United States would indeed agree to join Europe in adopting serious emission targets. Simultaneously, in the same agreement, China, India, and other developing countries would agree to a path that immediately imposes on them binding emission targets as well-but targets that in the first period simply follow the so-called business-as-usual path. BAU is defined as the

\footnotetext{
2 Technically the Copenhagen Accord and Cancun Agreements are not building a successor regime to the Kyoto Protocol, because they include quantitative commitments from developing countries whereas the Kyoto Protocol continues to exist and continues to apply only to so-called Annex I countries. The sooner the two separate tracks are integrated, the better. In this study, when we speak of a workable successor to Kyoto we are talking about a regime that includes developing countries.
} 
path of increasing emissions that these countries would experience in the absence of an international agreement, preferably as determined by experts' projections.

Of course an environmental solution also requires that China and other developing countries subsequently make cuts below their BAU path in future years, and eventually make cuts in absolute terms as well. The sequence of negotiation can become easier over time, as everyone gains confidence in the framework. But the developing countries can be asked to make cuts in the future that do not differ in nature from those made by Europe, the United States, and others who have gone before them, taking due account of differences in income. Emission targets can be determined by formulas that:

(i) give lower-income countries more time before they start to cut emissions,

(ii) lead to gradual convergence across countries of emissions per capita over the course of the century, and

(iii) take care not to reward any country for joining the system late.

We have proposed a set of formulas of this sort in past research and have projected the possible economic environmental effects by means of the WITCH model. The choice of parameters in Frankel (2009) allowed the world to achieve global concentrations of $500 \mathrm{ppm} \mathrm{CO} 2$ in the year 2100, while the estimated economic costs obeyed two political constraints: no single country or region is expected to bear a loss of more than $5 \%$ of income in any given period nor to bear a loss of more than $1 \%$ of income in terms of present discounted value. The choice of parameters in Bosetti and Frankel (2012) was more aggressive, to attain somewhat ambitious environmental goals at higher economic costs. 
The present study revises and updates our exercise along a variety of dimensions. As a result of the Copenhagen Accord and Cancun Agreements, we now have undertakings from more than 80 countries, including numerical goals not just for the EU 27 but also for 13 other Annex I countries (advanced countries plus a few former members of the Soviet Bloc) and - most importantly - for 7 big emerging markets: Brazil, China, India, Indonesia, Mexico, South Africa, and South Korea. Thus we have a firmer numerical basis on which to extrapolate what sorts of emission targets are politically reasonable.

The WITCH model has been recalibrated to reproduce the most updated dataset for the economy and the technologies. Ongoing revisions of the WITCH model have been necessary to take into account such economic developments as the 2008-09 global recession and such climate policy developments as the agreed or contemplated inclusion of other gases, forestation, biomass, and carbon capture and storage. India has been broken out separately, so we now have twelve countries or regions instead of eleven. Other refinements to the WITCH model include accounting for lost income for oil producers (which works to raise cost estimates), and new estimates of alternative technologies such as wind, bio energy, and CCS (which works to reduce cost estimates). ${ }^{3}$ The climate model has also been updated, with a better effort to account for aerosols.

In this study we adopt a criterion for measuring each country's economic costs that better suits the fundamental Nash theory of the sustainability of cooperative agreements. In the classic prisoner's dilemma, the two players are doomed to the Nash

\footnotetext{
${ }^{3}$ Previously, the WITCH model had not treated wind power independently from solar energy, and there had been no allowance for intermittency. Similarly, the possibility of CCS with gas is now included in all results. BE with CCS, which refers to the technology of woody bio-mass with carbon capture and storage and has the potential for negative emissions, is included in some of our results, where it is explicitly identified.
} 
non-cooperative equilibrium if each calculates that he will be better off defecting from the cooperative equilibrium even if the other does not defect. But the cooperative equilibrium is sustainable if every participant figures that the benefits of continuing to cooperate outweigh the costs, taking the strategies of the others as given. We will use the phrase "Nash criterion" to describe the way of measuring economic costs to each country of participating in the agreement relative to an alternative strategy of dropping out while others stay in.

Although the prospect of free riding works against the incentive to cooperate for most countries, our results suggest that the estimated economic cost of cooperation for those few regions that previously appeared to be at the greatest risk of defection is smaller than expected. If one assumes that all countries face some (small) penalty for defecting, perhaps moral opprobrium or tariffs on carbon-intensive exports, then it might be possible to sustain a cooperative equilibrium.

We also continue to explore the possibility of more aggressive environmental targets in our projections. The resulting estimated economic costs are high. But since national leaders have officially agreed on a goal of limiting global warming to 2 degrees Celsius, the economist who wants to make himself or herself useful will see if there exist ways to achieve such goals that are more practical than other ways.

\section{A Framework to Set Emissions Targets for All Countries and All}

\section{Decades}


Virtually all the many existing proposals for a post-Kyoto agreement are based on scientific environmental objectives (e.g., stabilizing atmospheric $\mathrm{CO}_{2}$ concentrations at $380 \mathrm{ppm}$ in 2100), ethical/philosophical considerations (e.g., the principle that every individual on earth has equal emission rights), economic cost-benefit analyses (weighing the economic costs of abatement against the long-term environmental benefits), or some combination of these considerations. ${ }^{4}$ This paper studies a way to allocate emission targets for all countries, for the remainder of the century, that is intended to be more practical in that it is also based on political considerations, rather than on science, ethics or economics alone. ${ }^{5}$

\section{Before Copenhagen}

At the 2007 UNFCCC Conference of Parties in Bali, governments agreed on a broad long-term goal of cutting total global emissions in half by 2050 . At a 2009 meeting in L'Aquila, Italy, the G8 leaders agreed to an environmental goal of limiting the temperature increase to $2^{\circ} \mathrm{C}$, which is thought to correspond roughly to a GHG concentration level of $450 \mathrm{ppm}$ (or approximately $380 \mathrm{ppm} \mathrm{CO} 2$ only).

\footnotetext{
${ }^{4}$ Important examples of the science-based approach, the cost-benefit-based approach, and the rights-based approach, respectively, are Wigley (2007), Nordhaus (1994, 2008), and Baer et al. (2008).

${ }^{5}$ Chakravarty, et al (2009) and German Advisory Council on Global Change (2009) propose gradual convergence of per capita targets. Llavador, Roemer and Silvestre (2011) propose convergence in welfare per capita. Numerous others have offered their own thoughts on postKyoto plans, at varying levels of detail, including Aldy, Orszag, and Stiglitz (2001); Aldy and Stavins (2008); Barrett (2006); Barrett and Stavins (2003); Bierman, Pattberg, and Zelli (2010); Birdsall, et al (2009); Carraro and Egenhofer (2003); Kolstad (2006); Nordhaus (2006); Olmstead and Stavins (2006), Seidman and Lewis (2009) and Stern (2007, 2011). Aldy, Barrett, and Stavins (2003) and Victor (2004) review a number of existing proposals. Aldy et al (2010) offers a more comprehensive survey.
} 
These meetings did not come close to producing agreement on who will cut how much in order to achieve the lofty stated goals. Further, the same national leaders are unlikely still to be alive or in office when realistic multilateral targets to reach these goals would come due. For this reason, the aggregate goals set out in these contexts cannot be viewed as anything more than aspirational.

Industrialized countries did, in 1997, agree to national quantitative emissions targets for the Kyoto Protocol's first budget period, so in some sense we know that agreements on specific emissions restrictions are possible. But nobody has ever come up with an enforcement mechanism that simultaneously imposes serious penalties for noncompliance and is acceptable to member countries. Given the importance countries place

on national sovereignty it is unlikely that this will change. Hopes must instead rest on relatively weak enforcement mechanisms such as the power of moral suasion and international opprobrium or possibly trade penalties against imports of carbon-intensive products from non-participants. It is safe to say that in the event of a clash between such weak enforcement mechanisms and the prospect of a large economic loss to a particular country, aversion to the latter would likely win out.

\section{A framework to last a century}

Unlike the Kyoto Protocol, the plan studied here seeks to bring all countries into an international policy regime on a realistic basis and to look far into the future. But we cannot pretend to see with as fine a degree of resolution at a century-long horizon as we can at a five- or ten-year horizon. Fixing precise numerical targets a century ahead is impractical. Rather, there will have to be a century-long sequence of negotiations, fitting 
within a common institutional framework that builds confidence as it goes along. The framework must have enough continuity so that success in the early phases builds members' confidence in each other's compliance commitments and in the fairness, viability, and credibility of the process. Yet the framework must be flexible enough that it can accommodate the unpredictable fluctuations in economic growth, technology

development, climate, and political sentiment that will inevitably occur. Only by striking the right balance between continuity and flexibility can a framework for addressing climate change hope to last a century or more.

\section{Political constraints}

We take five political constraints as axiomatic:

1. The United States will not commit to quantitative targets if China and other major developing countries do not commit to quantitative targets at the same time. (This leaves completely open the initial level and future path of the targets.) Any plan will be found unacceptable if it leaves the less developed countries free to exploit their lack of GHG regulation for "competitive advantage" at the expense of the participating countries' economies and leads to emissions leakage at the expense of the environmental goal.

2. China, India, and other developing countries will not make sacrifices they view as

a. fully contemporaneous with rich countries,

b. different in character from those made by richer countries who have gone before them,

c. preventing them from industrializing, 
d. failing to recognize that richer countries should be prepared to make greater economic sacrifices than poor countries, or

e. failing to recognize that the rich countries have benefited from an "unfair advantage" in being allowed to achieve levels of per capita emissions that are far above those of the poor countries.

3. In the short run, emission targets for developing countries must be computed relative to current levels or BAU paths; otherwise the economic costs will be too great for the countries in question to accept. But if post-1990 increases were permanently "grandfathered," then countries that have not yet agreed to cuts would have a strong incentive to ramp up emissions in the interval before they joined. Countries cannot be rewarded for having ramped up emissions far above 1990 levels, the reference year agreed to at Rio and Kyoto. Of course there is nothing magic about 1990 but, for better or worse, it is the year on which Annex I countries have until now based their planning. ${ }^{6}$

4. No country will accept a path of targets that is expected to cost it more than $Y$ percent of income throughout the $21^{\text {st }}$ century (in present discounted value). For now, we set $Y$ at 1 percent.

5. No country will accept targets in any period that are expected to cost more than $X$ percent of income to achieve during that period; alternatively, even if targets were

\footnotetext{
${ }^{6}$ If the international consensus were to shift the base year from 1990 to 2005, our proposal would do the same. Ten countries that accepted targets at Kyoto continued at Cancun to define their targets relative to 1990, including the EU (counted as one country). Australia shifted to 2000 as its point of reference, Canada and the US to 2005. The latter three countries are reflecting the reality of current emission levels that are by now very far above their 1990 levels. But our Latecomer Catchup Factor fulfills the same function.
} 
already in place, no country would in the future actually abide by them if it found the cost to doing so would exceed $X$ percent of income. For now, we set $X$ at 5 percent.

Of the above propositions, even just the first and second alone seem to add up to a hopeless stalemate: Nothing much can happen without the United States, the United States will not proceed unless China and other developing countries start at the same time, and China will not start until after the rich countries have gone first. There is only one possible solution; only one knife-edge position satisfies the constraints. At the same time that the United States agrees to binding emission cuts in the manner of Kyoto, China and other developing countries agree to a path that immediately imposes on them binding emission targets - but these targets in their early years simply follow the BAU path.

In later decades, the formulas we consider do ask substantially more of the developing countries. But these formulas also obey basic notions of fairness, by asking only for cuts that are analogous in magnitude to the cuts made by others who began abatement earlier and by making due allowance for developing countries' low per capita income and emissions and for their baseline of rapid growth. These ideas were developed in earlier papers ${ }^{7}$ which suggested that the formulas used to develop emissions targets incorporate four or five variables: 1990 emissions, emissions in the year of the negotiation, population, and income. One might also include a few other special variables such as whether the country in question has coal or hydroelectric power -though the 1990 level of emissions conditional on per capita income can largely capture these special variables -- and perhaps a dummy variable for the transition economies.

\footnotetext{
${ }^{7}$ Frankel $(1999,2005,2007)$ and Aldy and Frankel (2004). Some other authors have made similar proposals.
} 
We narrow down the broad family of possible formulas to a manageable set, by the development of the three factors: a short-term Progressive Reductions Factor, a medium-term Latecomer Catch-up Factor, and a long-run Gradual Equalization Factor. We then put them into operation to produce specific numerical targets for all countries, for all remaining five-year budget periods of the $21^{\text {st }}$ century. Next, these targets are fed into the WITCH model to see the economic and environmental consequences. International trading plays an important role. The framework is flexible enough that one can adjust a parameter here or there-for example if the economic cost borne by a particular country is deemed too high or the environmental progress deemed too lowwithout having to abandon the entire framework.

\section{Estimation of Business As Usual path}

One must acknowledge that BAU paths are neither easily ascertained nor immutable. Countries may "high-ball" their BAU estimates in order to get more generous targets (though this may be difficult for those who have hitherto "low-balled" their claimed emissions path to appear virtuous global citizens). Even assuming that estimates are unbiased, important unforeseen economic and technological developments could occur between 2010 and 2020 that will shift the BAU trajectory for the 2020s, for example. Any number of unpredictable events have already occurred in the years since 1990. They include German reunification, the 1997-1998 East Asia crisis, the boom in the BRIC countries (Brazil, Russia, India, and China), the global financial crisis of 2008- 
2009 , and great volatility in world oil prices over the last decade including the spikes of 2008 and 2011.

A first measure to deal with the practical difficulty of setting the BAU path is to specify in the Kyoto-successor treaty that estimates must be generated by an independent international expert body, not by national authorities. A second measure, once the first has been assured, is to provide for updates of the BAU paths every budget period. Allowing for periodic adjustments to the BAU baseline does risk undermining the incentive for carbon-saving investments, on the logic that such investments would reduce future BAU paths and thus reduce future target allocations. This risk is the similar to the risk of encouraging countries to ramp up their emissions. That is why we introduce a Latecomer Catch-up Factor into the formula which rapidly diminishes the weight assigned to BAU after a few budget periods and instead tethers countries to their 1990 emission levels in the medium run.

\section{The Post-Copenhagen Submissions as Starting Points}

Countries are expected to agree to the second step, quantitative targets that entail specific cuts below BAU, at a time determined by their circumstances. In our initial simulations, the choice of year for introducing an obligation actually to cut emissions was generally guided by two thresholds: when a country's average per capita income exceeds $\$ 3000$ per year and/or when its per capita annual emissions approach 1 ton or more. 
But we found that starting dates had to be further modified in order to satisfy our constraints regarding the distribution of economic losses.

As already noted, this approach assigns emission targets in a way that is more sensitive to political realities than other proposed target paths. Specifically, numerical targets are based (a) on commitments that political leaders in various key countries have already proposed or adopted, as of December 2010, and (b) on formulas designed to assure latecomer countries that the emission cuts they are being asked to make represent no more than their fair share -- in that they correspond to the sacrifices that other countries before them have already made.

\section{The Cancun targets}

Table 1 summarizes the quantitative targets submitted under the Copenhagen Accord and recognized in Cancun in December 2010. Most countries defined their targets relative to their 1990 emission levels (as was done in the Kyoto Protocol), some relative to a more recent base year (usually 2005) and some relative to BAU (a baseline that is more subject to interpretation). When evaluating the Latecomer Catch-up Factor, we will want to express targets relative to 1990 . When evaluating the Progressive Reduction Factor, we express the targets relative to BAU as estimated by the WITCH model (not by the country itself), shown in the last two columns of the table. For all non-OECD countries we assume that caps imposed before 2025 are no more stringent than BAU levels. Even though a few individual countries expressed readiness for caps that bind more sharply at Copenhagen and Cancun (e.g., Brazil's 2020 pledges), we do 
not feel that it would be appropriate to extend such commitments to the entire region in which such countries are located (e.g., Latin America).

\section{Targets for $\boldsymbol{E U}$}

Brussels in 2008 committed unilaterally to reduce European Union emissions 20 percent below 1990 levels by $2020{ }^{8}$ But the European Union (EU) also said it would cut emissions 30 percent below 1990 levels by 2020, conditional on other countries joining in. Thus, given assumptions on other countries' commitments, we now set an EU target of 30 percent below 1990 levels. EU targets continue their downward trajectory in the third period, 2020-2025, to 35 per cent below 1990 levels and then progress in equal increments to a level 50 percent below in the eighth period, 2045-2050.

\section{Target for Japan}

Japan's Copenhagen pledge for 2020 is 25 percent below 1990 levels, which is 29 percent below 2005 levels. This is the same as what he had assumed previously, based on prime ministers' statements.

\section{Target for US}

The American submission under the Copenhagen Accord is 2020 emissions at $17 \%$ below 2005 levels (which would represent the achievement of the Kyoto goal of 5\% below 1990 levels, but delayed by an entire decade). We had previously taken our cue from bills in the US Congress in assuming that emissions were targeted roughly to flatten

\footnotetext{
${ }^{8}$ Documentation of pre-Copenhagen legislation or announcements by leaders in the EU and other national governments is given in the footnotes to the 2009 working paper version of Bosetti and Frankel (2012).
} 
between 2012 and 2020. This is more aggressive than that with respect to the near term, which is consistent with the evidence $\mathrm{n}$ the meantime that American emissions peaked in 2007, as a result of the ensuing recession. The Congressional bills had been aggressive in the longer term, and we follow them in assuming a year-2050 target that is $83 \%$ below the 2005 level.

\section{Targets for Korea, South Africa and Australia}

These three coal-dependent countries are grouped together. We had previously assumed that the Korean target would show flat emissions from 2005 to 2020 . But Korea has persisted with more aggressive targets: its Cancun submission for 2020, though defined as 30 percent below BAU, translates to $18 \%$ below 2005 emissions. Similarly with South Africa: phrased as 34 percent below BAU, it translates to $23 \%$ below 2005 . Australia is having great difficulty making up its mind. Its targets could lie anywhere from $11 \%$ to $32 \%$ below 2005 . We take the South African target, 34 per cent below BAU, to represent the threesome.

\section{Targets for Latin America}

Mexico, preparing for the Cancun meeting in December 2010, felt the usual host's obligation to make a significant offer. Mexico and Brazil both suggested 2020 targets phrased relative to BAU. Brazil's is the more aggressive, translating to 34 to 37 per cent below 2005 levels. We assume that, although pledges for Brazil are stricter, Latin America overall is not yet prepared to undertake any cuts below BAU. We assume that 
the region is prepared to start cutting below BAU in 2040, or in 2025 when we turn to a more aggressive scenario.

\section{Targets for East Asia}

East Asia is a category that here excludes Japan, China and Korea; thus it is really Southeast Asia. Its largest member is Indonesia. Indonesia's Copenhagen target, translated from BAU terms, is in the range 24 to 39 per cent below 2005 levels by 2020 . But, again, we assume that the larger region is not yet prepared to be this aggressive. We continue to give BAU targets to the Southeast Asians until 2060, or until 2025 in the more ambitious case.

Table 1: Quantitative emission targets for 2020 submitted at Cancun under the Copenhagen Accord

\begin{tabular}{|c|c|c|c|c|c|c|c|c|c|c|c|c|c|c|c|c|c|c|}
\hline \multirow{3}{*}{ Country } & \multirow{3}{*}{ Pledge at COP15 } & \multicolumn{9}{|c|}{ Greenhouse Gases Emissions (GT CO2-eq) } & \multicolumn{8}{|c|}{ Copenhagen Pledges } \\
\hline & & \multicolumn{3}{|c|}{ Excluding LULUCF } & \multicolumn{3}{|c|}{ LULUCF } & \multicolumn{3}{|c|}{ Total } & \multicolumn{2}{|c|}{ Target } & \multicolumn{2}{|c|}{ wrt $1990(\%)$} & \multicolumn{2}{|c|}{ wrt $2005(\%)$} & \multicolumn{2}{|c|}{ wrt BaU (\%) } \\
\hline & & 1990 & 2005 & 2020 & 1990 & 2005 & 2020 & 1990 & 2005 & 2020 & LC & $\mathrm{HC}$ & LC & $\mathrm{HC}$ & LC & $\mathrm{HC}$ & LC & $\mathrm{HC}$ \\
\hline Australia & $-5 \%,-15 \%$ to $-25 \%$ wrt 2000 & 0.42 & 0.53 & 0.62 & 0.02 & 0.02 & 0.01 & 0.44 & 0.54 & 0.63 & 0.48 & 0.37 & $11 \%$ & $-15 \%$ & $-11 \%$ & $-32 \%$ & $-23 \%$ & $-41 \%$ \\
\hline Belarus & $-5 \% / '-10 \%$ wrt 1990 & 0.14 & 0.08 & 0.10 & 0.00 & 0.00 & 0.00 & 0.14 & 0.09 & 0.10 & 0.13 & 0.13 & $-6 \%$ & $-11 \%$ & $56 \%$ & $48 \%$ & $29 \%$ & $22 \%$ \\
\hline Canada & $-17 \%$ wrt 2005 & 0.59 & 0.73 & 0.83 & 0.02 & 0.04 & 0.04 & 0.62 & 0.77 & 0.88 & 0.65 & 0.65 & $6 \%$ & $6 \%$ & $-16 \%$ & $-16 \%$ & $-26 \%$ & $-26 \%$ \\
\hline Croatia & $-5 \%$ wrt 1990 & 0.03 & 0.03 & 0.04 & 0.00 & 0.00 & 0.00 & 0.03 & 0.03 & 0.04 & 0.03 & 0.03 & $-5 \%$ & $-5 \%$ & $-2 \%$ & $-2 \%$ & $-20 \%$ & $-20 \%$ \\
\hline Euro 27 & $-20 \% /-30 \%$ wrt 1990 & 5.57 & 5.12 & 6.13 & 0.02 & 0.01 & 0.02 & 5.59 & 5.13 & 6.15 & 4.47 & 3.91 & $-20 \%$ & $-30 \%$ & $-13 \%$ & $-24 \%$ & $-27 \%$ & $-36 \%$ \\
\hline Iceland & $-30 \%$ wrt 1990 & 0.00 & 0.00 & 0.00 & 0.00 & 0.00 & 0.00 & 0.00 & 0.00 & 0.00 & 0.00 & 0.00 & $-30 \%$ & $-30 \%$ & $-36 \%$ & $-36 \%$ & $-44 \%$ & $-44 \%$ \\
\hline Japan & $-25 \%$ wrt 1990 & 1.27 & 1.35 & 1.54 & 0.02 & 0.02 & 0.02 & 1.29 & 1.38 & 1.57 & 0.98 & 0.98 & $-24 \%$ & $-24 \%$ & $-29 \%$ & $-29 \%$ & $-38 \%$ & $-38 \%$ \\
\hline Kazakhstan & $-15 \%$ wrt 1992 & 0.36 & 0.24 & 0.26 & 0.00 & 0.00 & 0.00 & 0.36 & 0.24 & 0.26 & 0.31 & 0.31 & $-16 \%$ & $-16 \%$ & $29 \%$ & $29 \%$ & $18 \%$ & $18 \%$ \\
\hline New Zealand & $-10 \%$ to $-20 \%$ wrt 1990 & 0.06 & 0.08 & 0.09 & 0.00 & 0.00 & 0.00 & 0.06 & 0.08 & 0.09 & 0.06 & 0.05 & $-9 \%$ & $-19 \%$ & $-28 \%$ & $-36 \%$ & $-37 \%$ & $-44 \%$ \\
\hline Norway & $-30 \% /-40 \%$ wrt 1990 & 0.05 & 0.05 & 0.06 & 0.00 & 0.00 & 0.00 & 0.05 & 0.05 & 0.06 & 0.03 & 0.03 & $-32 \%$ & $-42 \%$ & $-36 \%$ & $-46 \%$ & $-44 \%$ & $-52 \%$ \\
\hline Russian Federation & $-15 \% /-25 \%$ wrt 1990 & 3.32 & 2.12 & 2.31 & 0.06 & 0.04 & 0.01 & 3.38 & 2.16 & 2.32 & 2.83 & 2.50 & $-16 \%$ & $-26 \%$ & $31 \%$ & $16 \%$ & $22 \%$ & $8 \%$ \\
\hline Switzerland & $-20 \% /-30 \%$ wt 1990 & 0.05 & 0.05 & 0.06 & 0.00 & 0.00 & 0.00 & 0.05 & 0.05 & 0.06 & 0.04 & 0.04 & $-23 \%$ & $-32 \%$ & $-22 \%$ & $-31 \%$ & $-32 \%$ & $-40 \%$ \\
\hline Turkey & BaU & 0.19 & 0.33 & 0.40 & 0.00 & 0.00 & 0.00 & 0.19 & 0.33 & 0.40 & 0.40 & 0.40 & $115 \%$ & $115 \%$ & $22 \%$ & $22 \%$ & -- & -- \\
\hline Ukraine & $-20 \%$ wit 1990 & 0.93 & 0.42 & 0.52 & 0.00 & 0.00 & 0.00 & 0.93 & 0.42 & 0.52 & 0.74 & 0.74 & $-20 \%$ & $-20 \%$ & $75 \%$ & $75 \%$ & $44 \%$ & $44 \%$ \\
\hline United States & $-17 \%$ wrt 2005 & 6.11 & 7.10 & 8.23 & 0.07 & 0.03 & 0.00 & 6.18 & 7.13 & 8.23 & 5.90 & 5.90 & $-5 \%$ & $-5 \%$ & $-17 \%$ & $-17 \%$ & $-28 \%$ & $-28 \%$ \\
\hline Brazil & $-0.97 /-1.05 \mathrm{GtCO}$-eq wrt BaU & 0.72 & 1.11 & 1.53 & 0.89 & 1.45 & 1.13 & 1.61 & 2.56 & 2.66 & 1.68 & 1.61 & $4 \%$ & $0 \%$ & $-34 \%$ & $-37 \%$ & $-37 \%$ & $-40 \%$ \\
\hline China & arbon intensity of output by $40-45 \%$ & 3.72 & 7.61 & 10.75 & 0.04 & 0.03 & -0.28 & 3.76 & 7.64 & 10.47 & 10.47 & 10.47 & $179 \%$ & $179 \%$ & $37 \%$ & $37 \%$ & -- & -- \\
\hline India & arbon intensity of output by $20-25 \%$ & 1.33 & 2.05 & 2.59 & 0.05 & 0.04 & 0.01 & 1.38 & 2.09 & 2.60 & 2.60 & 2.60 & $89 \%$ & $89 \%$ & $24 \%$ & $24 \%$ & - & -- \\
\hline Indonesia & $-26 \% /-41 \%$ wrt BaU & 0.45 & 0.73 & 1.13 & 0.4 & 0.84 & 0.49 & 0.86 & 1.57 & 1.62 & 1.20 & 0.96 & $40 \%$ & $12 \%$ & $-24 \%$ & $-39 \%$ & $-26 \%$ & $-41 \%$ \\
\hline Mexico & Mt CO2-eq /-30\% wrt BaU & & 0.61 & & & & & & 0.6 & & 0.82 & 0.6 & $71 \%$ & $27 \%$ & $26 \%$ & $-6 \%$ & $-6 \%$ & $-30 \%$ \\
\hline South Africa & $-34 \%$ wrt BaU & 0.34 & 0.44 & 0.51 & 0.00 & 0.00 & 0.0 & 0.35 & 0.44 & 0.51 & 0.34 & 0.34 & $-2 \%$ & $-2 \%$ & $-23 \%$ & $-23 \%$ & $-34 \%$ & $-34 \%$ \\
\hline South Korea & $-30 \%$ wrt BaU & 0.30 & 0.67 & 0.79 & 0.00 & 0.00 & 0.00 & 0.30 & 0.67 & 0.79 & 0.55 & 0.55 & $84 \%$ & $84 \%$ & $-18 \%$ & $-18 \%$ & $-30 \%$ & $-30 \%$ \\
\hline
\end{tabular}

Source: Calculations based on Business as Usual (BaU) scenarios of the WITCH model prepared for the The Emission Gap Report, United Nations Environment Program; adjustments were made when countries are not individually represented in the WITCH model .

\section{Targets for China and India}

In important breakthroughs, China and India announced targets after Copenhagen.

They expressed the targets in terms of intensity (carbon emissions divided by GDP). We, 
as others, estimate that these targets translate approximately into these countries' respective BAU paths. Environmentalists and American business interests may complain that these important countries do not propose to cut emissions below what they would be in the absence of an international agreement. But this has been our plan all along for China and India in the near term. The important thing is to cap their emissions and get them in the trading system. Targets below BAU come later.

Environmentalists and businessmen may come to realize that the commitment, even though only a commitment to BAU targets, is more important than it sounds. It precludes the carbon leakage which, absent such an agreement, would undermine the environmental goal, and it ameliorates the competitiveness concerns of carbon-intensive industries in rich countries. A commitment to BAU targets would provide assurance that developing countries will not exploit the opportunity to go above their BAU paths, as they might in the absence of this commitment.

Our approach recognizes that it would be politically difficult to get China to agree to substantial actual cuts in the short term. Indeed China might well continue to register strong objections to being asked to take on legally binding targets of any kind at the same time as the United States. But the Chinese may be coming to realize that they would actually gain from such an agreement, by acquiring the ability to sell emission permits at the same world market price as developed countries. (China currently receives lower prices for lower-quality project credits under the Kyoto Protocol's Clean Development Mechanism.)

How do we know they would come out ahead? China is currently building roughly 100 power plants per year, to accommodate its rapidly growing demand. In the 
absence of environmental policy, most would continue to run on cheap coal. The cost of shutting down an already-functioning coal-fired power plant in the United States is far higher than the cost of building a new clean low-carbon plant in China in place of what otherwise might be a new dirty coal-fired plant. Because of this gap in costs, when an American firm pays China to cut its emissions voluntarily, thereby obtaining a permit that the American firm can use to meet its emission obligations, both parties benefit in strictly economic terms.

\section{Targets for former Soviet republics}

Four countries report emission targets that actually work out to constitute increases above their BAU paths. These are not developing countries, but rather countries that were once part of the Soviet Union: Russia, Ukraine, Belarus and Kazakhstan. Their

proposed cuts appear as the four points below the zero axis in Figure 1a. In the case of Ukraine, the proposed target is a full $44 \%$ above its current BAU. This is because the targets keyed to 1990 for these countries were rendered obsolete, based on the judgment that their economies had collapsed following the collapse of the Soviet Union. These countries are seeking a continuation of the "hot air" that they received under the Kyoto Protocol.

One sometimes hears claims that the hot air for these countries agreed at Kyoto was inadvertent. After all, it created the potential for them to sell permits and thus get paid for emission reductions that had already occurred for reasons unrelated to the environment. This concession was in fact not inadvertent, but was judged by other delegations to be necessary to induce the former Soviet countries to agree to the Kyoto 
Protocol. (An additional factor in this calculation was that Russia arguably has much less of a stake in avoiding global warming than do most other countries.) The fact that other delegations judged this concession warranted in 1997 does not necessarily mean that an extension of it is warranted again today.

We will consider two cases, one where the targets for the four former Soviet countries are set equal to BAU (as estimated by us, not the countries themselves), similarly to the lower-income countries, and another where they are given the extra benefits implicit in their Cancun submissions. ${ }^{9}$

\section{“Fair" emission targets}

Economists usually try to avoid the word "fair," since it means very different things to different people. In the context of climate change policy, "fair" to industrialized countries implies that they shouldn't have to cut carbon emissions if the emissionproducing industries are just going to relocate to developing countries that are not covered by the targets. Our plan addresses this concern by assigning targets to all countries, rich and poor, even if in some cases they are only BAU targets. "Fair" to developing countries means that they shouldn't have to pay economic costs that are different in nature than those paid by industrialized countries before them, taking into account differences in income. Our plan addresses this concern by including in the formula the Progressive Reductions Factor, which in the early years assigns to richer

\footnotetext{
${ }^{9}$ The first draft of the paper presented the first case, i.e., no hot air. When it comes to computing the economic costs of emission targets for the more stringent policy we investigate here, we find that the Transition Economies incur high costs unless they are given the early hot air or some other benefit to ease the burden, so we allow let them keep their hot air in the more stringent policy scenario. (Their costs are almost as high as for the MENA countries, and for the same reason: according to the new version of the WITCH model, oil producers pay a heavy price for the climate change regime.)
} 
countries targets that cut more aggressively relative to BAU, as well as the Gradual Equalization Factor, which dictates that in the long run all countries converge in the direction of equal emission rights per capita.

\section{Estimating the degree of progressivity}

Our first statistical exercise is to run a regression of the cuts implied by the Copenhagen-Cancun targets against the countries' current income per capita. We expect to find a positive statistical relationship between income per capita and the emission cuts, under the hypothesis that it is reasonable from a political economy viewpoint for countries to make deeper percentage cuts relative to BAU the richer they are. This is the progressive relationship that was uncovered in the Kyoto targets (Frankel, 1999, 2009): The targets agreed among Annex I countries at Kyoto in 1997, including among members of the EU considered separately, implied an estimated progressivity parameter of 0.14 . Running the regression on the Copenhagen-Cancun numbers could be viewed either as an exercise in hypothesis-testing or as an exercise in parameter estimation. If our hypothesis -- that it is reasonable as a matter of political economy to expect countries in their first year of emission cuts to accept larger cuts relative to BAU the higher their income -- is correct, then this progressive pattern should again show up in the numbers

recorded under the Cancun Agreements. Alternatively, we could use the regression to obtain a new estimate of the progressivity parameter. 
Figure 1a: Estimated progressivity in Cancun targets, including former Soviet countries

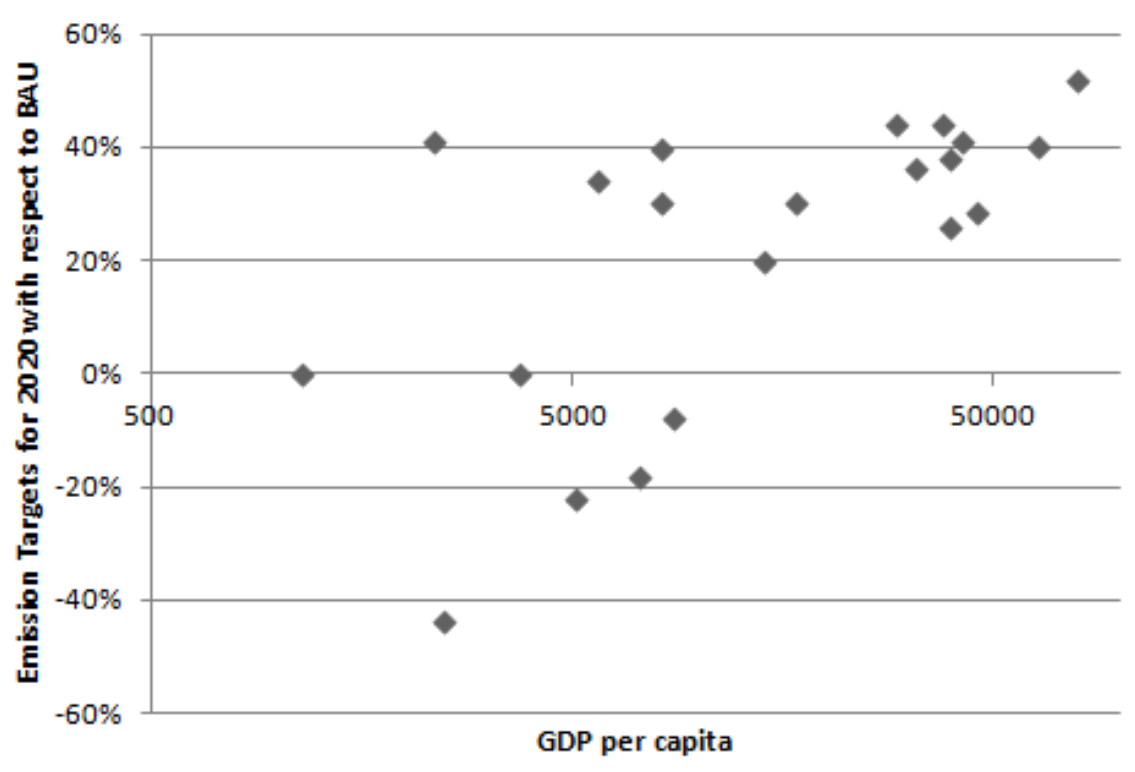

$y=0.16$

$t=3.7$

$\mathrm{R}^{2}=.42$

Sources: WITCH model Projections

Figure 1b: Estimated progressivity in Cancun targets, setting former Soviet country targets to BAU

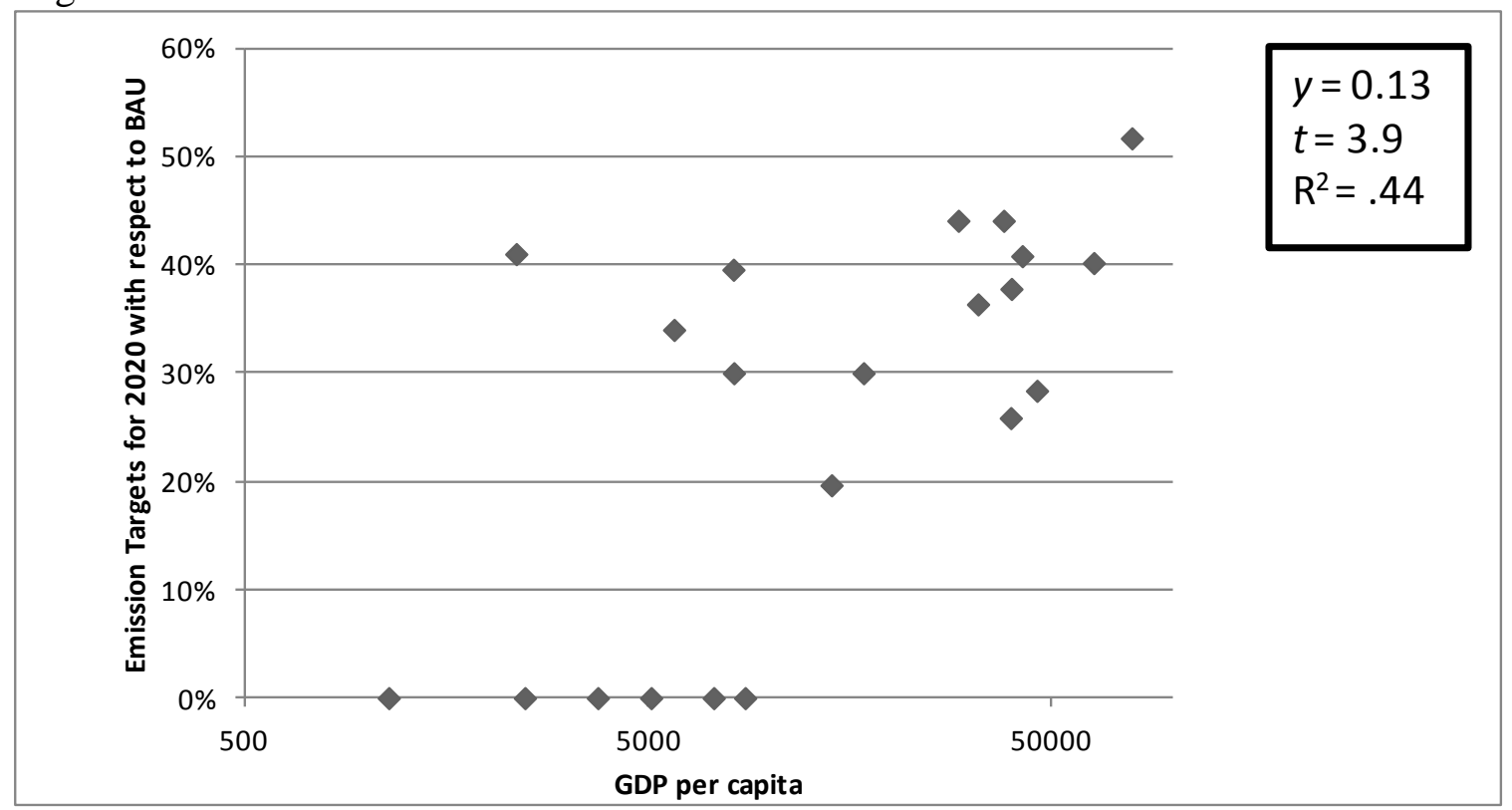

Sources: WITCH model Projections 
In Table 2a we regress emission cuts (from BAU) against income per capita, including all the Cancun targets, corresponding to Figure 1a. Progressivity is highly significant: the t-statistic is 3.7 and the $\mathrm{R}^{2}$ is .42 . The estimated parameter is .16 . When we eliminate excess over BAU in the emission targets for the four former Soviet countries as illustrated in Figure $1 \mathrm{~b}$, the results are even more highly significant. The tstatistic is 3.9 and the $\mathrm{R}^{2}$ is .44 . The estimated parameter is .13. This is an encouraging result. The estimated progressivity parameter is not just statistically significant, but extraordinarily close to the estimate on a very different set of numbers determined 13 years earlier, at the time of the Kyoto Protocol. The current estimates, .13 and .16, bracket the earlier estimate, .14. We are happy with this bit of external validation of the theory. We see no need to update the estimate of the progressivity parameter $\gamma$ used in the model, since the new estimates lie so close to the old one.

\section{Table 2a: Estimation of Progressivity}

\begin{tabular}{|c|c|c|c|c|}
\hline \multicolumn{5}{|c|}{$\begin{array}{c}\text { Cancun emission target cuts, expressed relative to BAU, } \\
\text { regressed against income per capita } \\
\text { (21 country observations, counting EU } 27 \text { as one })\end{array}$} \\
\hline & \multicolumn{4}{|c|}{ Countries submitting negative cuts relative to BAU are: } \\
\hline & \multicolumn{2}{|c|}{ taken at face value } & \multicolumn{2}{|c|}{ set $=0$} \\
\hline & Intercept & $\gamma$ & Intercept & $\gamma$ \\
\hline Coefficient estimate & 0.018 & -0.162 & 0.008 & -0.130 \\
\hline Standard error & 0.065 & 0.043 & 0.050 & 0.034 \\
\hline t-statistic & 0.07 & -3.72 & 0.16 & -3.87 \\
\hline $\mathrm{P}$ value & 0.789 & 0.001 & 0.878 & 0.001 \\
\hline
\end{tabular}




\begin{tabular}{|l|l|l|}
\hline $\mathrm{R}^{2}$ & 0.421 & 0.441 \\
\hline
\end{tabular}

Next we use the Copenhagen-Cancun submissions to estimate the parameters for latecomer catch-up at the same time as the progressivity parameter, in Table $2 \mathrm{~b}$.

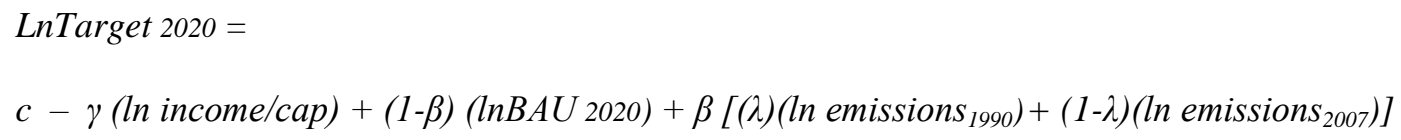

where

$\gamma \equiv$ progressivity

$(1-\beta) \equiv$ weight on BAU

$\lambda \equiv$ strength of latecomers' catch-up.

We estimate the formula shown in equation (1) by running the regression:

$($ LnTarget $2020-\ln B A U 2020)=$

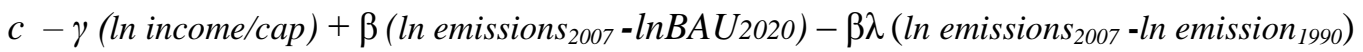

\section{Table 2b: Estimation of progressivity and latecomer catch-up factors}

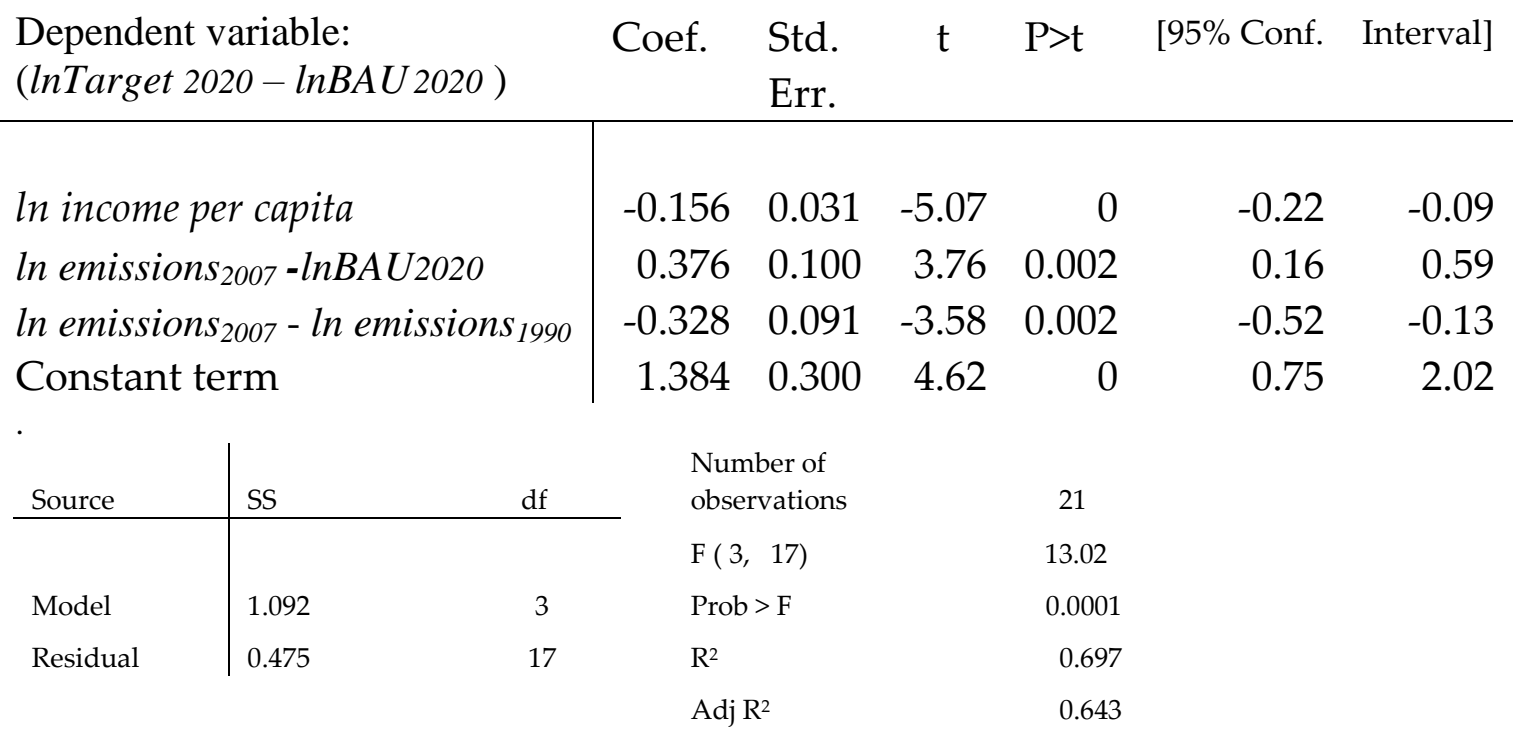


All three coefficients come out showing the hypothesized sign and high statistical significance. This looks like further evidence in favor of our political economy theory. Indeed, one could hardly have wished for a stronger outcome of the hypothesis test. The point estimates of the coefficients are $c=1.384, \gamma=0.156, \beta=0.376$, and $\beta \lambda=0.328$. The progressivity parameter is still very close to its preceding value $\gamma=0.16$, even though we are now controlling for other factors. Take the ratio of the last two coefficients to get the estimate $\lambda=0.872$. We will use these estimates to update the parameters in our formulas.

\section{Constructing the formula and parameters}

Our approach is to assume that countries determine whether to join the climate change regime and to abide by any agreement by balancing the costs and benefits, broadly interpreted. The benefits to a given country from participating are not modeled. But they include country's contribution to mitigating global climate change itself (which is not important for small countries), auxiliary benefits such as the environmental and health effects of reducing local air pollution, the avoidance of international moral opprobrium, and perhaps the avoidance of trade penalties against non-participants.

\section{Constraints on economic costs}


The costs of participating are economic. The benefits that some countries get from the right to sell emission permits are explicitly counted within (net) economic costs.

As noted, we capture the cost-benefit calculation by interpreting political constraints as precluding that a country agrees to participate if the targets would impose an economic cost greater than $Y \%$ of income in terms of present discounted value. In other words, $Y$ can be interpreted as the sum of the benefits of participation. If costs exceed benefits, the country will defect. We further assume that political constraints preclude that a country will continue to comply with an agreement if the targets would impose a cost in any one period greater than $X \%$ of income. In Frankel (2009), $X$ was set at $5 \%$ of income, and $Y$ at $1 \%$. Bosetti and Frankel (2012) allowed looser constraints.

What is the benchmark to which each country compares participation when evaluating its economic costs? In our previous work, we assumed that the alternative to participation is BAU: what the world would look like if there had never been a serious climate change agreement in the first place. This may indeed be the relevant benchmark, especially when the $X$ threshold for the present discounted value of cost is interpreted as determining whether countries agree to the treaty ex ante, each conditional on the others agreeing. Treaties like the Kyoto Protocol do not go into effect unless a particular high percentage of parties ratify the treaty. There was room for no more than one large holdout.

In the context of the Nash criterion, however, one could argue that cooperation is unlikely to be sustained when each individual country calculates that if it were to defect from the agreement on its own, with others continuing to abide by the agreement, the benefits of defecting would outweigh the benefits of participation. It is not enough to 
calculate that bringing down the entire global agreement would inflict high costs. The concern is that individual temptations to free-ride will torpedo cooperation, even though cooperation is in the collective interest.

Therefore we introduce here a new interpretation of the political constraint. Each country calculates the economic benefit of dropping out of an agreement under the assumption that the rest continue to participate, which we call the Nash criterion for evaluating the economic cost of participating. If that economic benefit exceeds $\mathrm{X} \%$ of GDP in any given year, the country will drop out. In that case - perhaps - the entire agreement will unravel, as other countries make similar calculations. If this weakness is perceived from the beginning, then the agreement will never achieve credibility in the first place. ${ }^{10}$

The Nash criterion may sound like a more difficult test to meet than the earlier one. If one adds the gains from free-riding to the costs of compliance with an agreement, then it sounds less likely that we will find $500 \mathrm{ppm}$ or any other given environmental target to satisfy the constraint that economic costs remain under the threshold for sustainable cooperation. But that would be to view the question solely from the viewpoint of the many countries for whom a viable international climate regime is a good thing. From the viewpoint of most oil producers, any international climate regime reduces the demand for fossil fuels and so probably leaves them worse off. Free riding on others' efforts is not a meaningful concept in their case. For the oil producers, therefore, defining the benchmark as the case where they drop out alone but the rest of the world stays in produces lower estimated costs to abiding by the agreement. The global oil price is going

\footnotetext{
${ }^{10}$ Among those emphasizing the "time inconsistency" of leaders' promises to cut emissions in the future are Helm et al (2003).
} 
to go down regardless. This could make the cost-benefit test easier to meet than under the earlier criterion. ${ }^{11}$

MENA shows up with far higher costs than was true in our earlier research. The reason is that many countries in the Middle East and North Africa are oil exporters, and the current version of the WITCH model pays more attention to the economic costs imposed on oil producers from a decline in world demand for fossil fuels. We presume these cost estimates to be well-founded; therefore to get them down we now grant MENA a later starting date. The same is true to an extent of costs estimated for the Transition Economies and Canada. When pursuing the more ambitious environmental goal, in Section 7, we let the TE countries keep the hot air that is implicit in their Cancun submissions, in order to bring down their costs. Among the countries not considered oil producers, the category that includes Korea, South Africa and Australia generally shows the highest costs, especially toward the end of the century. This turns out to be attributable to an assumption of the model that these countries include deposits of "unconventional oil" that become profitable later in the century, but that is penalized by a climate change regime along with the conventional oil producers. We are not convinced that the potential for these "oil grades 7 and 8 " is necessarily well-founded and so we have chosen to emphasize in our simulations a version of the model that omits them, with the result that costs are not so high for Korea, South Africa and Australia.

\footnotetext{
${ }^{11}$ The test of sustainability becomes easier to satisfy if the oil exporters are the ones who are otherwise in most danger of violating the $X$ and $Y$ thresholds. This in fact turns out to be the case in our estimates. (The test would become harder to satisfy if the other countries, those that want a climate change regime to work, are the ones who are most in danger of violating the $X$ and $Y$ thresholds.)
} 


\section{Choice of parameters}

We perform our analysis with values for $\lambda$ and other parameters based on the econometric estimation of the equation parameters from the Copenhagen-Cancun submissions (i.e., the coefficients estimated in Table $2 \mathrm{a}$ ). We round off to $\lambda=0.9$ the estimate from Table $2 \mathrm{a}$ for the latecomer catch-up factor in the first budget period during which a country accepts targets below BAU.

We have all along intended that the latecomer catch-up process would be complete within a few decades, in other words that the partial accommodation accorded to countries that have ramped up their emissions between 1997 and 2012 would not be long-lasting. Thus where we extend the analysis to modify parameter values in light of the Copenhagen-Cancun submissions, we will set $\lambda=1.0$ in the second period of cuts for any given country (call it year $\tau$ ), so that the equation in that case becomes:

$($ LnTarget $\tau-\ln B A U \tau)=c-\gamma($ income $/$ cap $)+\beta\left(\ln B A U \tau-\ln\right.$ emissions $\left._{1990}\right)$

In words, the level of emissions in 2007 drops out of the equation as early as the second period of cuts for any given country. The formula for the target in this case becomes a weighted average of BAU and 1990 (minus the usual Progressive Reduction Factor). We can round off to 0.4 the parameter $\beta$ (which is now the weight placed on 1990 emissions, versus BAU). Needless to say, spurious precision in these parameter choices would not be appropriate.

The third component of the formula is the Gradual Equalization Factor (GEF). Beginning in 2050 we switch to a formula that in each period sets assigned amounts in 
per capita terms, as follows: a weighted average of the country's most recent assigned amount and the global average, with a weight of $\delta$ on the latter. In past work we set $\delta=0.1$, so that the speed of convergence across countries was $1 / 10$ per five-year budget period. In Section 5 here, when the environmental goal is year-2100 concentrations of $\mathrm{CO} 2$ equal to $500 \mathrm{ppm}$, we set the constant term $\mathrm{c}=0.8^{12}$ and $\delta=0.11$. When we turn to a more stringent environmental goal, we adjust the constant term down to $\mathrm{c}=0.3$ for all countries and the GEF weight back down to $\delta=0.10$.

\section{The numerical emission target paths that follow from the formulas}

Table 2 reports the emissions targets produced by the formulas for each of twelve geographical regions, for every period between now and the end of the century.

The twelve regions are:

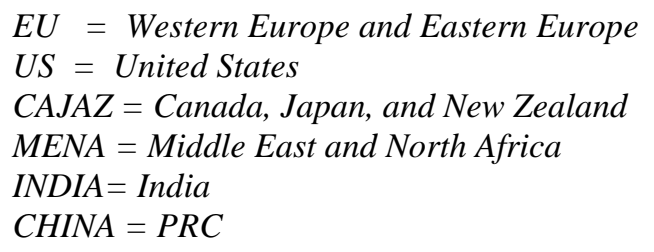

\author{
EASIA = Smaller countries of East Asia \\ $K O S A U=$ Korea, South Africa, and Australia \\ $T E=$ Russia and other Transition Economies \\ $S S A=$ Sub-Saharan Africa \\ $S A S I A=$ rest of South Asia \\ $L A M=$ Latin America and the Caribbean
}

\footnotetext{
${ }^{12}$ We make an exception to our general practice of applying a uniform formula to all: we give the TE group a constant term of 0.5 rather than 0.8 (to allow for the special circumstances of their obsoletely high emissions in 1990).
} 
Table 3: Target starting points for the 12 modeled regions (the case of 500 ppm goal)

\begin{tabular}{|c|c|c|}
\hline & 2020 & 2050 \\
\hline EU & 30\% below 1990 emissions & progress to $50 \%$ below 1990 \\
\hline USA & $17 \%$ below 2005 & $83 \%$ below 2005 \\
\hline Australia, S.Africa \& S.Korea & $34 \%$ below baseline & $50 \%$ below baseline \\
\hline Japan, Canada \& NZ & $25 \%$ below 1990 & as before \\
\hline $\mathrm{TE}$ & BAU & Cap based on formula in 2055 \\
\hline LAM & BAU & Cap based on formula in 2040 \\
\hline India & BAU & BAU (cap based on formula, from 2060) \\
\hline EASIA & BAU & BAU (cap based on formula, from 2060) \\
\hline SASIA & BAU & $\mathrm{BAU}$ \\
\hline CHINA & BAU & Cap based on formula in 2050 \\
\hline SSA & BAU & $\mathrm{BAU}$ \\
\hline MENA & BAU & Cap based on formula in 2065 \\
\hline
\end{tabular}

Figure 2: Global emission targets resulting from the formula, $500 \mathrm{ppm}$ goal

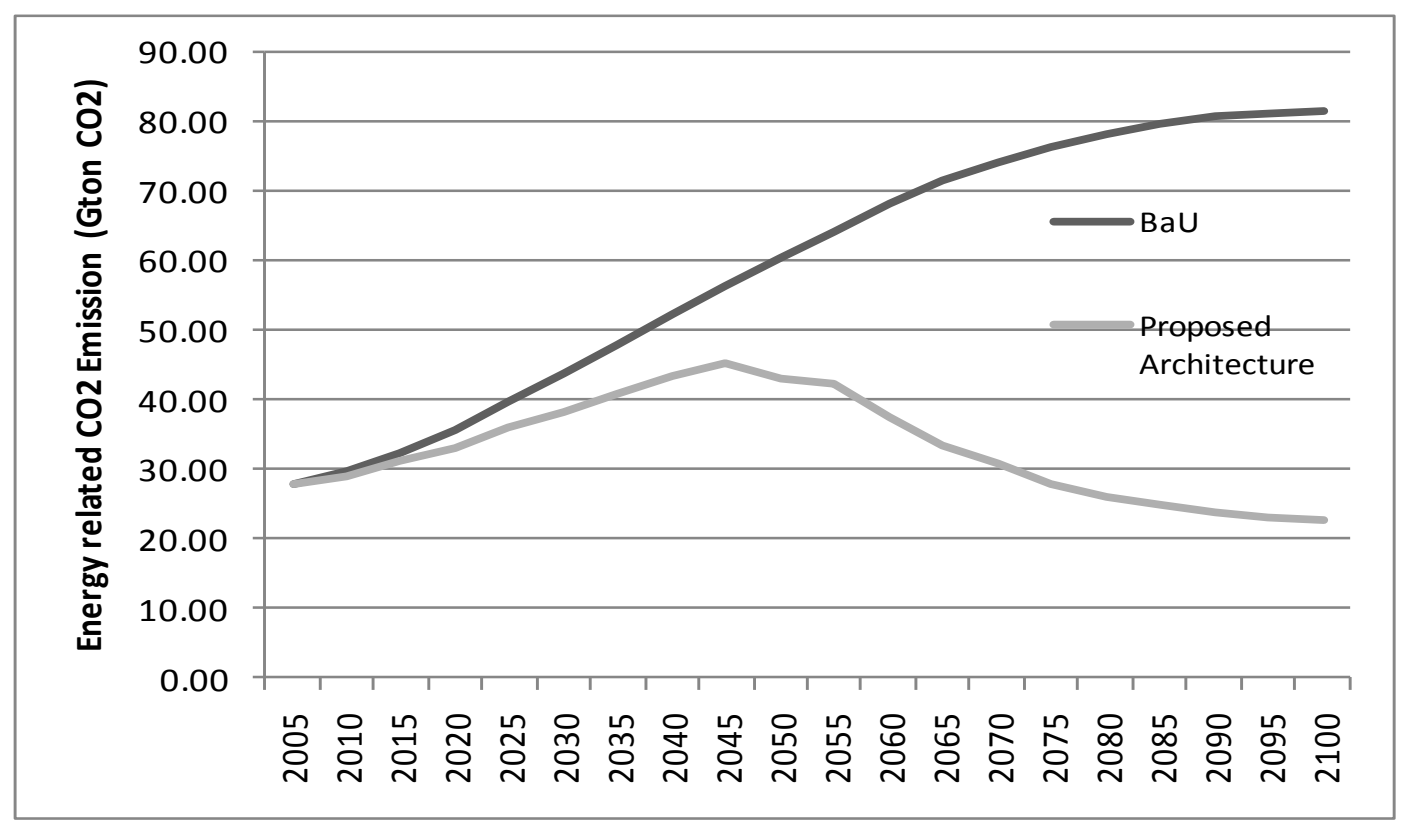


Starting at the most highly aggregated level, Figure 2 shows global emissions. The path is a bit more aggressive than in previous work, as a reflection of the pledges made at Cancun. The emissions peak comes in 2045. ${ }^{13}$ Cuts steepen after 2050, so that energy-related emissions worldwide fall from over 40 Gigatons (Gt) of CO2 in 2040 to 20 in $2100,1 / 4$ their BAU level.

How important is it that all countries/regions participate? If one country drops out and others respond by doing the same, so that the result is to unravel the entire agreement, then obviously the effect is very large. But what if just one country or region drops out, or fails to sign up in the first place? Figure 3 examines this question. The bottom path represents full cooperation, the same as in Figure 2: all countries sign up and continue to participate throughout the century. If South Asia alone refuses to play, the result is the next-lowest path; it hardly makes any difference for global emissions as these economies are small. If Canada, Japan and New Zealand are the only ones to drop out, the effect is just a bit more. And so on. The uppermost path shows what happens if China alone drops out. It represents a big jump over the second highest path (the case where India alone drops out), or the third highest (where the USA alone drops out). This illustrates that Chinese participation is the sine qua non of a successful global effort to address climate change, followed in importance by the participation of India and the United States. It is more than noteworthy that these three big countries did not accept targets under the Kyoto Protocol. ${ }^{14}$

\footnotetext{
${ }^{13}$ Remarkably, this happens to correspond to the cost-efficient path found by Manne and Richels (1996, 1997), wherein global emissions peak in 2040-2050.

${ }^{14}$ In each of the "Nash" simulations, where one country drops out at a time, it turns out that the free riding country emits less than it would in the BAU baseline. According to the WITCH
} 
Figure 3: Global emissions if one drops out, but cooperation otherwise continues

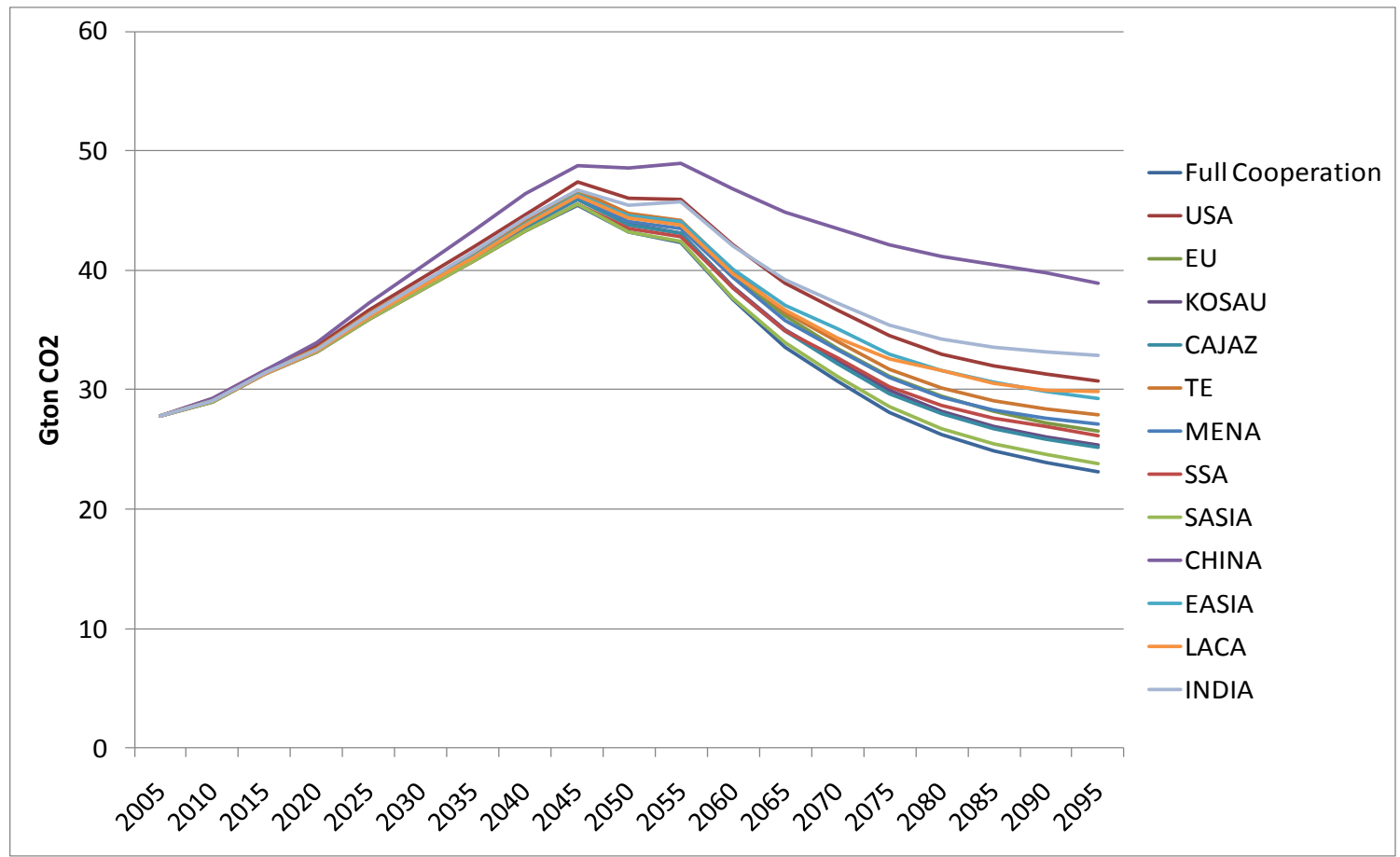

Figure 4a: Targets and emissions by OECD countries under the $500 \mathrm{ppm}$ goal

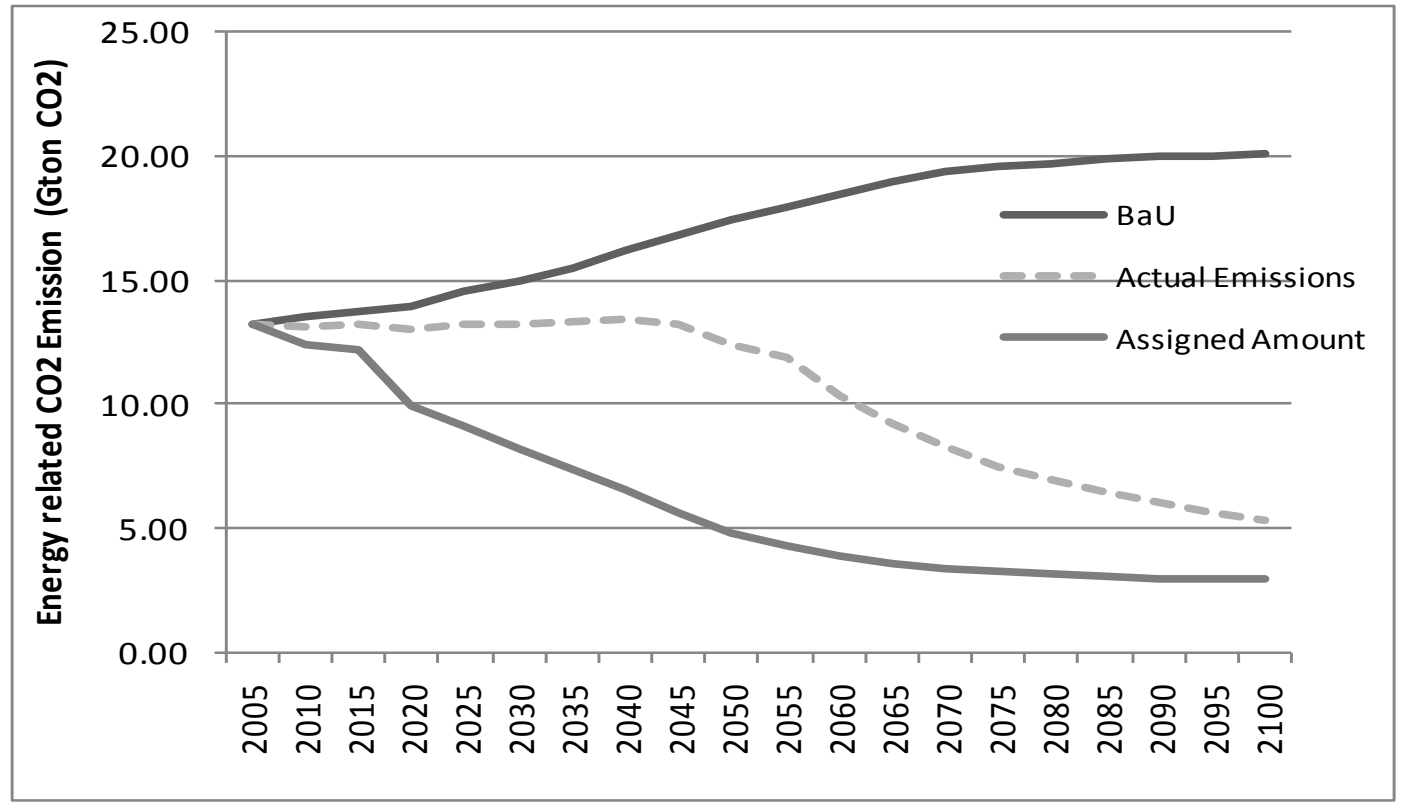

model, they take the opportunity from the cost improvements in the carbon free technologies among those countries that continue to participate and this outweighs the conventional leakage effects (according to which they consume more fossil fuels because the world price is reduced and they expand production in energy-intensive sectors because they gain a competitive advantage). 
Next we disaggregate between industrialized countries and developing countries. Figure 4a shows the former, defined now as members of the Organization for Economic Cooperation and Development (Annex I countries excluding TE). Emissions begin to decline as early as 2010, reflecting a real-world peaking of emissions around 2007 and recalibration of baselines caused in large part by the global recession that reduced industrial country activity sharply in 2009. ${ }^{15}$ (Targets go on to decline from about $13 \mathrm{Gt}$ of $\mathrm{CO} 2$ in 2010 to less than $3 \mathrm{Gt}$ of $\mathrm{CO} 2$ in 2100 . )

The graph also shows the simulated value for actual emissions of the rich countries, which decline more gradually than the targets through mid-century because carbon permits are purchased on the world market, as is economically efficient. The total value of the permit purchases runs about $6 \mathrm{Gt}$ of $\mathrm{CO} 2$ in the middle decades of the century and then declines.

Figure $4 \mathrm{~b}$ shows that among non-OECD countries overall, both emissions targets and actual emissions peak in 2045. The simulated path of actual emissions lies a little above the target caps. The difference, again, is the value of permits sold by the poor countries to the rich countries. Thanks to emission permit sales, actual emissions fall below the BAU path, though still rising well before developing countries are forced to cut by more aggressive targets after 2045 . The total falls from the peak of about $38 \mathrm{Gt}$ of energy-related $\mathrm{CO} 2$ emissions in 2045 to less than half that in 2100 . The year-2100 emissions are about one third of the BAU level for that year.

\footnotetext{
${ }^{15}$ That the peaking of rich-country emissions is attributable to the 2009 recession is consistent with the failure of most models to predict it (absent strong climate change policy). In Frankel (2009), emissions did not begin to fall until 2025. Even in the more aggressive policy scenario of Bosetti and Frankel (2012), they only peaked in 2010 and began to fall in 2015 .
} 
Figure 4b: Targets and emissions by developing countries under the $500 \mathrm{ppm}$ goal

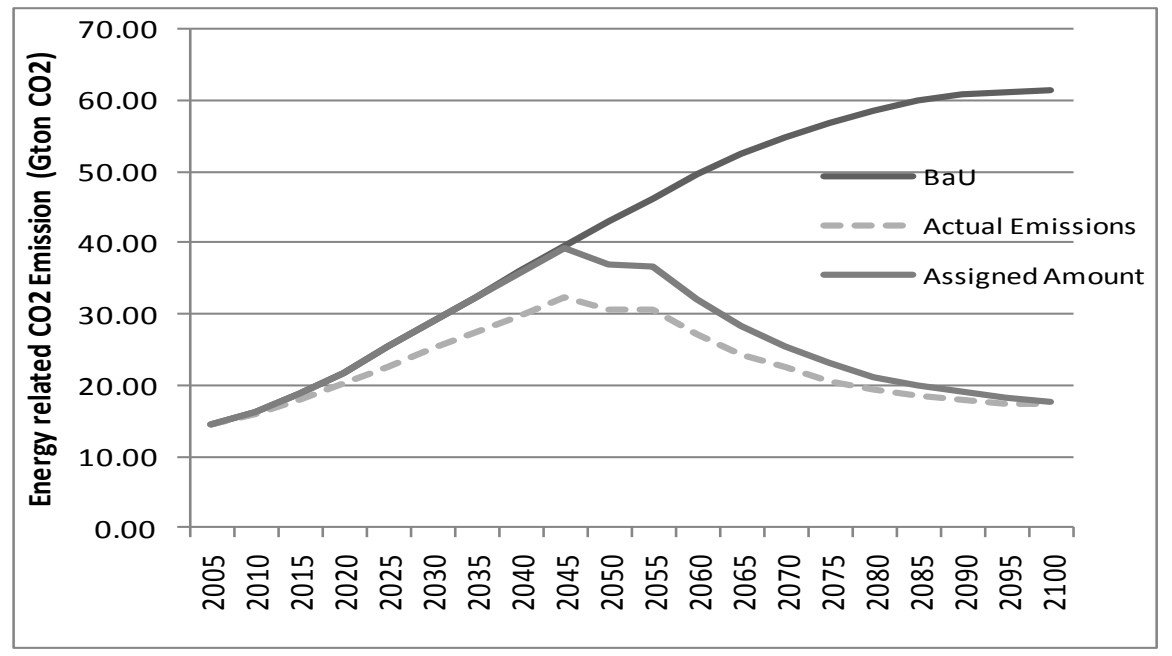

Other things equal, it is desirable that the rich countries not achieve too large a share of emission reductions in the form of permit purchases. The estimates for the size of the international market in carbon emission permits are presented in Appendix 2 (Figures $21 \mathrm{a}$ and $21 \mathrm{~b}$ for the $500 \mathrm{ppm}$ goal and Figures 22a and 22b for the more ambitious environmental goal.)

Figure 5: Per capita emission targets under the 500ppm goal

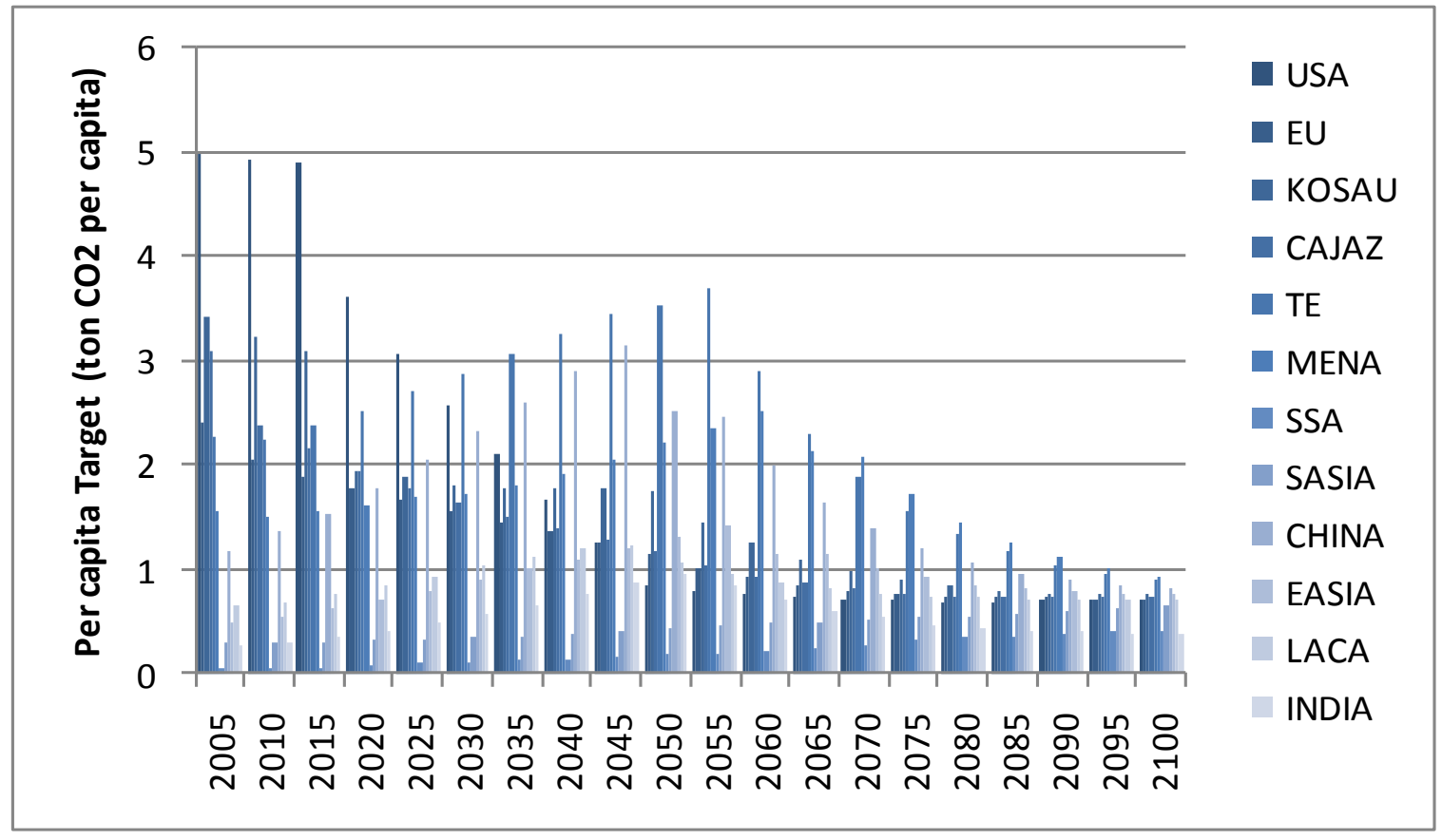


The bar chart in Figure 5 expresses emissions in per capita terms, for every region in every budget period. The United States, even more than other rich countries, is currently conspicuous by virtue of its high per capita emissions: close to 5 tons $\mathrm{CO} 2$ per capita. But they start to come down after 2015, like the other rich regions. Emissions in developing countries continue to rise for a bit longer, and then come down more gradually. But their emissions per capita numbers of course start from a much lower base. China peaks at almost 3 tons CO2 per capita in 2040. Most of the other developing countries rarely get above 1 ton $\mathrm{CO} 2$ per capita; India climbs just over 1 ton per capita briefly at the peak in 2060. In the second half of the century, everyone converges toward levels below one ton per capita, thanks to the gradual equalization formula.

\section{Consequences of the targets, according to the WITCH model}

We run these emission levels through the WITCH model to see the effects. Before we turn to the costs in terms of lost income, which is the measure of economic welfare that is relevant to economists, we look first at the effect on the price of energy, which is politically salient and also a good indicator of the magnitude of the intervention.

\section{Economic effects}

Figure 6 reports that the price of carbon remains quite reasonable through 2045, but then begins to climb steeply. By 2100 it surpasses $\$ 250$ per ton of CO2. Many in the business world would consider this a high price. The effect translates into an increase in 
the price for US gasoline around \$2.5 per gallon. Needless to say, this idea would be extremely unpopular, although the increment is on the same order of magnitude as petrol taxes today in Europe and Japan. ${ }^{16}$

\section{Figure 6: Effect on energy prices, under 500 ppm goal}

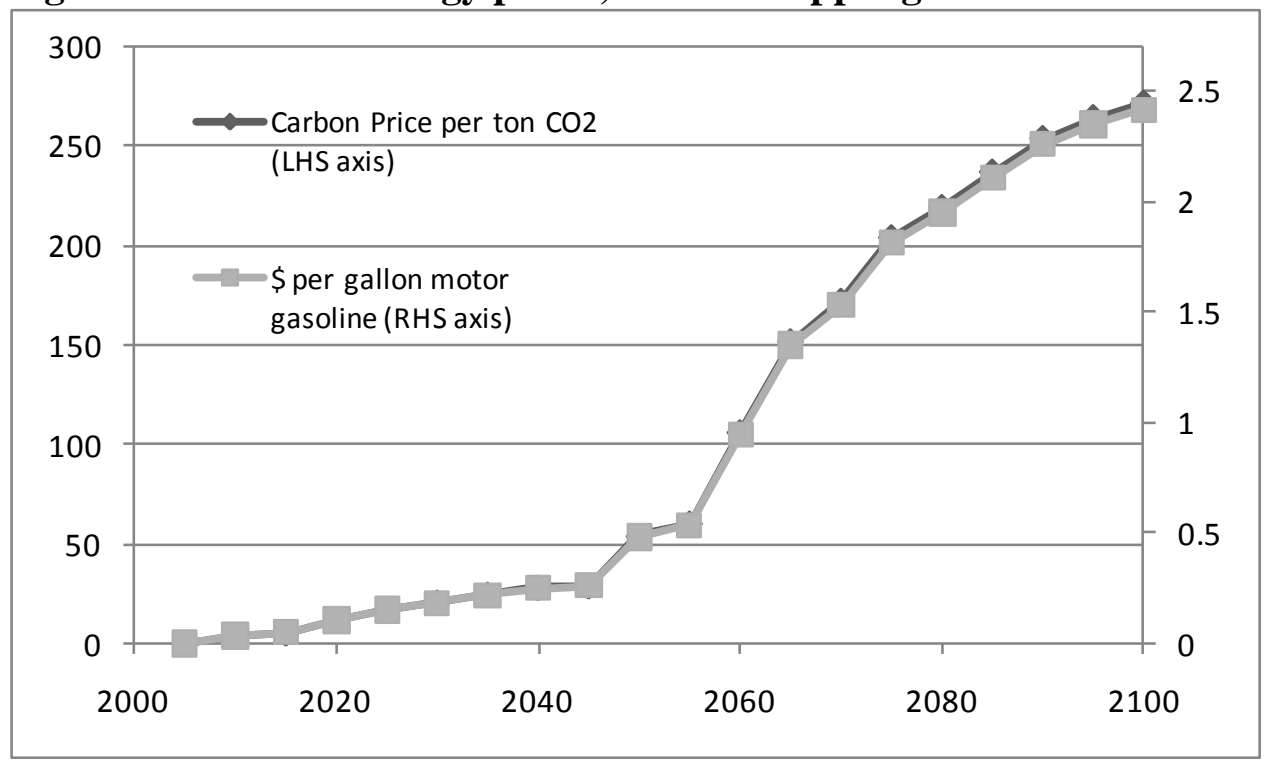

Global economic losses measured in terms of national income are illustrated in Figure 7a, for the case where bio energy with CCS is excluded. Cost rises gradually over time up to 2085 . Given a positive rate of time discount, this is a good outcome. ${ }^{17}$ As late as 2050 they remain below $1 \%$ of income. In the latter part of the century losses rise but never exceed $3 \%$ of income. Figure $7 \mathrm{~b}$ illustrates the case that allows for bio energy with CCS. Now global costs stay below 2.1 per cent of income even late in the century. Either way, the present discounted value of global costs is less than 0.7 per cent of income, using a discount rate of $5 \%$.

\footnotetext{
${ }^{16}$ The prices for carbon and gasoline here are substantially less than the prices estimated in Frankel (2009), let alone Bosetti and Frankel (2012). The explanation is partly the greater attention paid to wind and to gas plus CCS, but mainly because of BE with CCS. The lower number of carbon-free alternatives, the larger role for energy saving. The implication is a higher price of carbon but also lower amounts of carbon in the economy.

${ }^{17}$ Tol (1998).
} 
Figure 7a: Global economic costs (\% of income) of 500 ppm goal (without BE \& CCS)

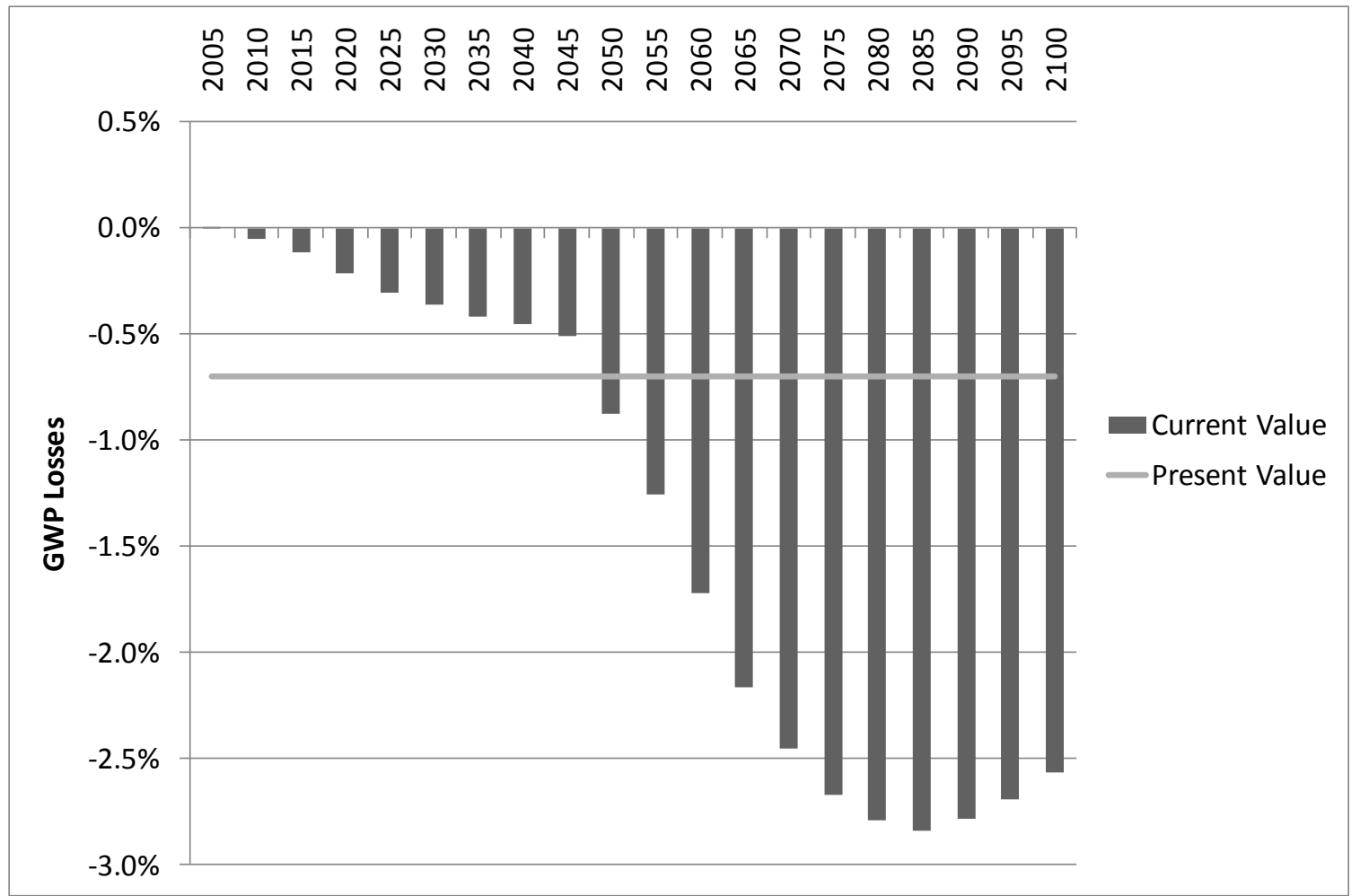

Figure 7b: Global economic costs (\% of income) of 500 ppm goal (with BE \& CCS)

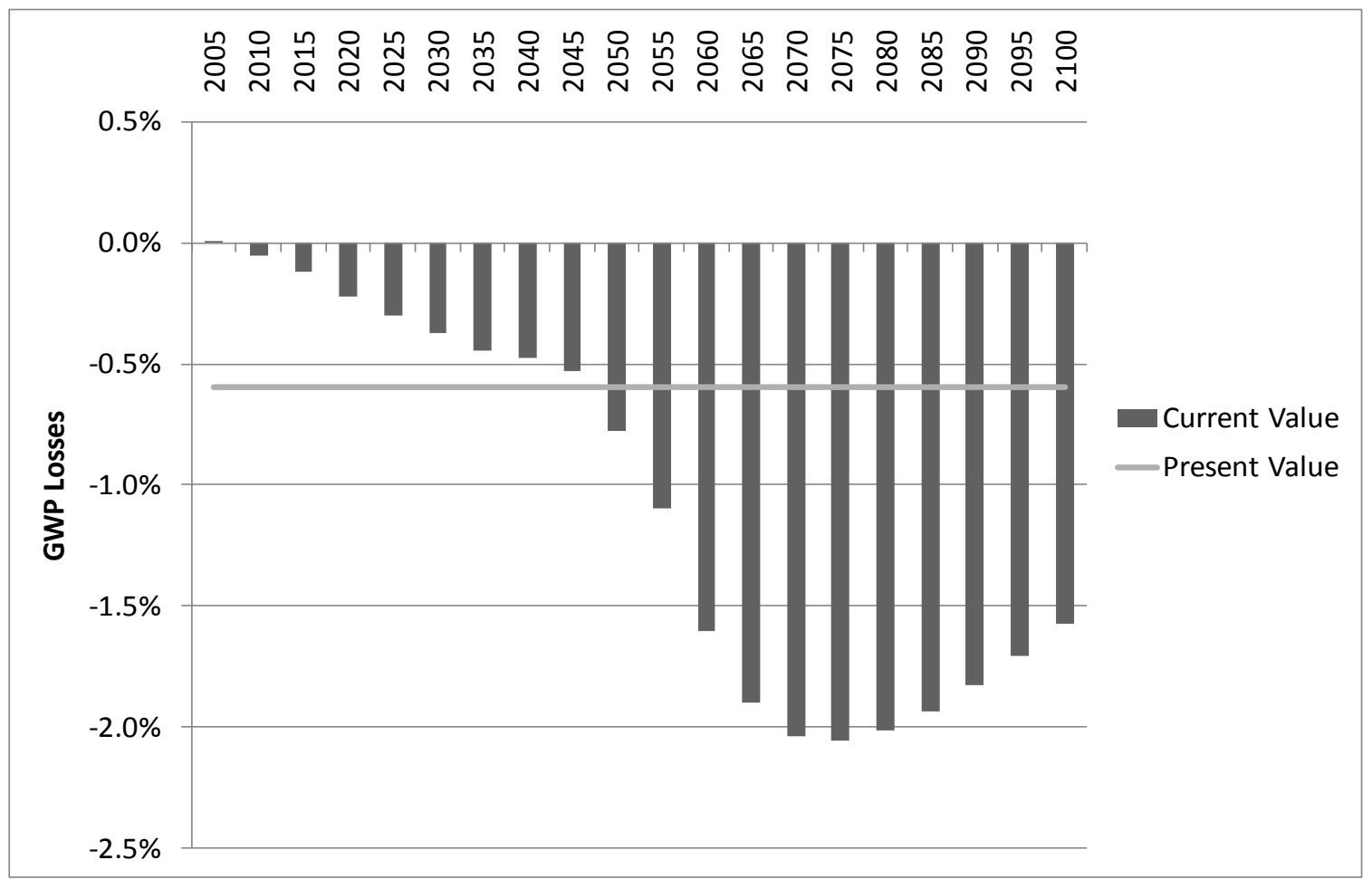


Figures $8 \mathrm{a}$ and $8 \mathrm{~b}$ report the economic costs country by country, for the first and second halves of the century, respectively.

Figure 8a:

Economic losses (\% of income) of each region, under $500 \mathrm{ppm}$ goal, 2010-2045

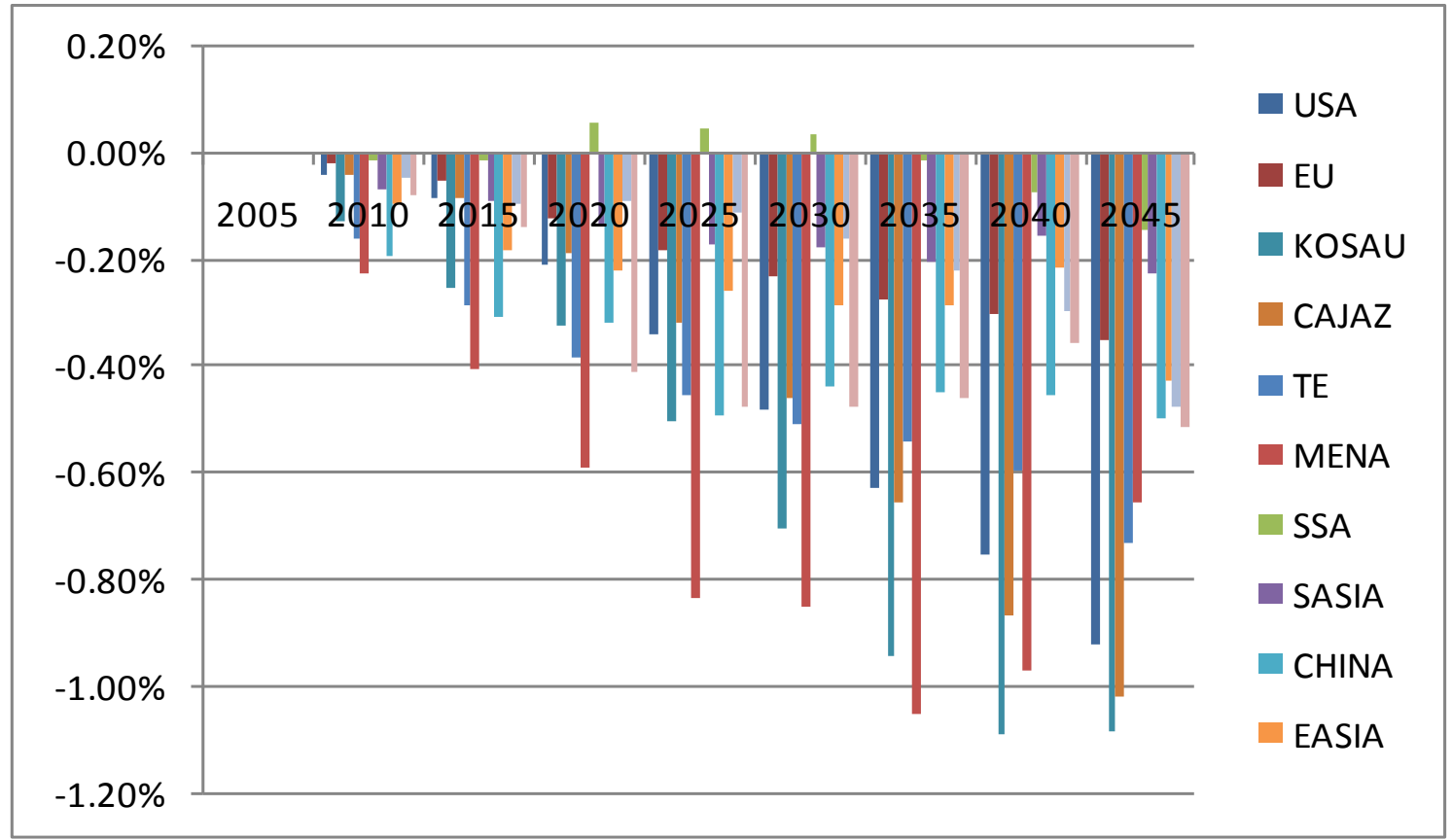

Figure 8b: Economic losses, 2050-2090

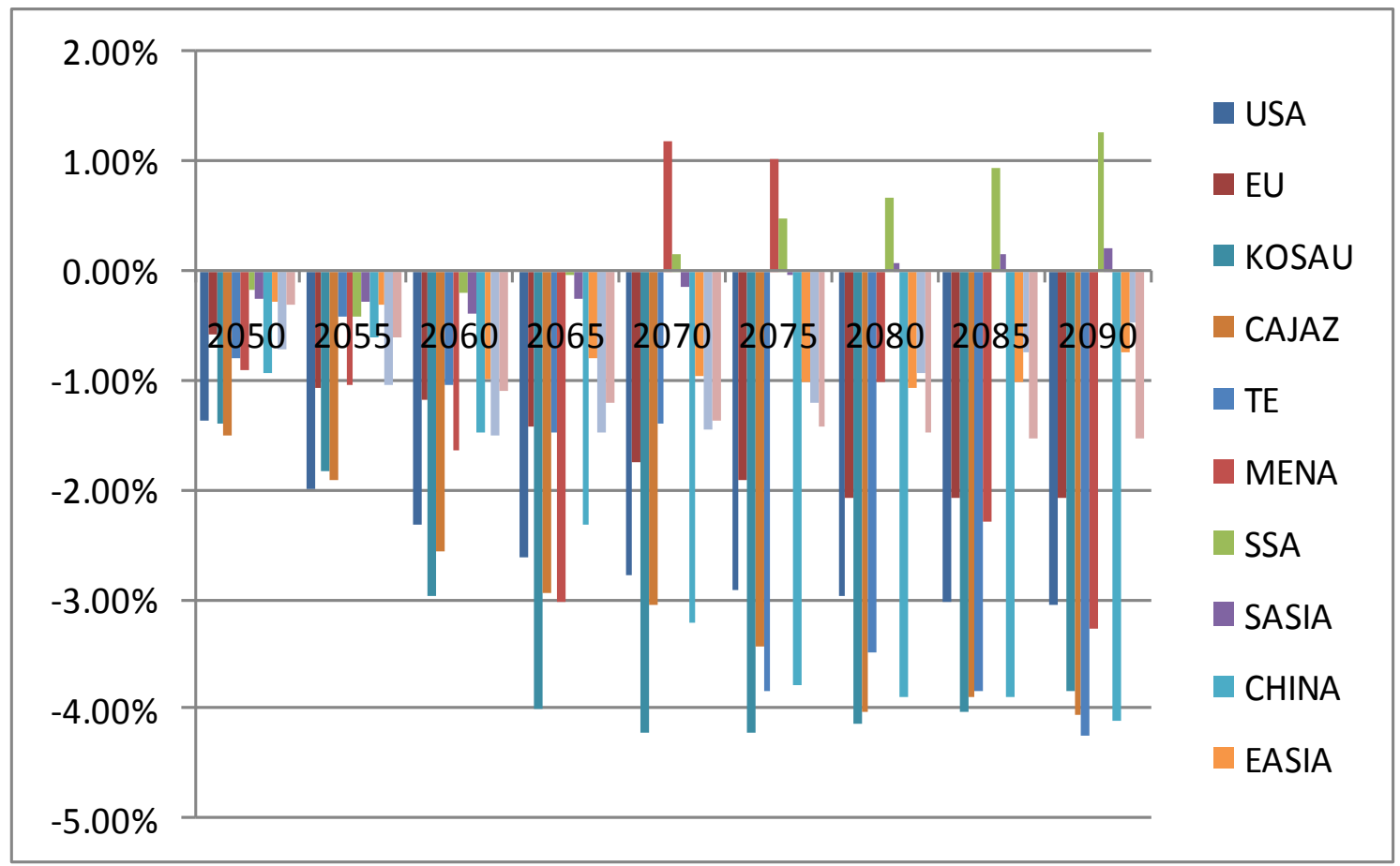


Until 2050 , costs remain below $1.2 \%$ of income for every country or region. In the second half of the century they rise, for the Annex I countries of Kyoto in particular. But for every country and in every budget period the cost remains under 5\% per cent of income. This is good news: it is the (admittedly arbitrary) threshold that we have used from the beginning, under the logic that no government could afford politically to continue to abide by an agreement that was costing the country more than 5 per cent of income. It would make no difference if such a country had benefited from permit sales in the early years or even suffered no loss at all in present discounted value; large potential losses in later years would render any earlier commitments "dynamically inconsistent."

Our other political constraint is that no government will sign its country up for an agreement that in ex ante terms is expected to cost more than a particular threshold, which Frankel (2009) - again arbitrarily - set at 1 per cent of income. Table 4 reports the present discounted value of economic losses for each country or region, using a discount rate of 5 per cent. In Table 4a the question is how much it costs the country in question to participate if the alternative is the case where there never was an operational international climate policy in the first place, in other words BAU. The range of economic burdens across countries is wide. It is close to zero for India and other poor countries. ${ }^{18}$ But it is as high as 2.2 percent of income for the Middle East and North Africa, well above our desired threshold, and 1.2 percent for the Transition Economies. ${ }^{19}$ It lies in between for the United States, at 0.6 percent of income.

\footnotetext{
18 Pakistan and other non-India countries in South Asia actually gain, from the ability to sell permits, as does Sub-Saharan Africa.

${ }^{19}$ The cost estimates for the two regions are higher than in past research, because the WITCH model has been revised to capture the losses to oil producing countries from a reduced global demand for fossil fuels.
} 
Table 4: Present discounted value of cost region by region (as percent of income)

4a: Measured relative to alternative baseline of no international policy (i.e., BAU criterion)

\begin{tabular}{|c|c|c|c|c|c|c|c|c|c|c|c|}
\hline USA & EU & KoSAu & CaJaZ & TE & MENA & SSA & SAsia & China & EAsia & LAm & India \\
\hline $0.6 \%$ & $0.2 \%$ & $0.7 \%$ & $0.7 \%$ & $1.2 \%$ & $2.2 \%$ & $-0.1 \%$ & $-0.2 \%$ & $1.1 \%$ & $0.1 \%$ & $0.5 \%$ & $0.4 \%$ \\
\hline
\end{tabular}

4b: Measured relative to the alternative of unilateral dropping out while others continue to cooperate (i.e., Nash criterion)

\begin{tabular}{|c|c|c|c|c|c|c|c|c|c|c|c|}
\hline USA & EU & KoSAu & CaJaZ & TE & MENA & SSA & SAsia & China & EAsia & LAm & India \\
\hline $0.7 \%$ & $0.3 \%$ & $0.8 \%$ & $0.6 \%$ & $0.8 \%$ & $0.8 \%$ & $-0.1 \%$ & $0.1 \%$ & $1.0 \%$ & $0.4 \%$ & $0.4 \%$ & $0.7 \%$ \\
\hline
\end{tabular}

One could argue that the relevant criterion in deciding whether cooperation is sustainable is not whether individual countries find the economic cost to be too high relative to an alternative where there was never any international policy action in the first place, but rather whether individual countries find the cost to be too high relative to a strategy where they drop out but others continue to cooperate (i.e. a game theoretic viewpoint).

We are not claiming to prove any theorems regarding sub-game perfect cooperative equilibria. But the spirit is that the international regime imposes moderate penalties for a country that does not participate, such as international opprobrium or trade penalties against imports of carbon-intensive products, and that these penalties are in the range of the thresholds $\mathrm{X}$ and $\mathrm{Y}$ (which we have been taking as 5\% and $1 \%$ of income, respectively). Under these assumptions, if the economic gain from dropping out measured by the Nash criterion is below the threshold, then cooperation would seem to be sustainable. Only if cooperation in future periods is seen to be sustainable ex ante will 
the agreement be credible from the beginning. Only if the agreement is credible will firms begin early to phase in new and existing low-carbon technologies, in anticipation of higher carbon costs in the future. Only if firms begin to phase in these technologies from the beginning will an emissions target path that begins slowly succeed in its motivation of reducing costs by allowing sufficient time for the capital stock to turn over.

Table $4 \mathrm{~b}$ estimates costs by the Nash criterion. The question is how much does it cost the country in question - considering each country one at a time - to participate if the alternative is the case where it drops out of the international agreement but the other countries continue to abide by it. One might expect that the prospect of free riding would entail substantial gains for the country dropping out, i.e., that continued participation would entail substantial costs. This is the essence of leakage. Indeed the costs are higher in Table $4 \mathrm{~b}$ than Table $4 \mathrm{a}$ for most of the countries, including most of the industrialized countries. But for the former members of the Soviet Bloc (TE) and especially for the MENA countries, the economic cost is much lower in Table $4 \mathrm{~b}$ than in Table 4a. The explanation is that, regardless what they themselves do, oil producers bear substantial losses when participating countries reduce their demand for fossil fuels. [In this sense, their cooperation is not really required.]

The effect of switching to the Nash criterion is to narrow the range of costs across regions, so that it runs only from 0.7 per cent of income for India to 0.8 per cent for MENA, TE and one per cent for China. This is very important. The importance does not stem primarily from equity considerations. If equity were the driving criterion then the benchmark would be not just a world in which no climate change policy is undertaken, but a world in which none is needed because there haven't been any greenhouse gas 
emissions in the first place. ${ }^{20}$ The importance stems, rather, from the game theory considerations: any country that bears especially high costs for continuing to participate is likely to drop out. But the high-cost countries are the same as those that lose rather than gain from free riding on the coalition. In Table $4 \mathrm{~b}$, the costs borne by the three highest country/regions - MENA, TE, and China - are in each case below 1 per cent of GDP, the $Y=1 \%$ threshold for every region.

The economic losses in Figures 8a and 8b were measured according to the Nash criterion as well. That is, the bar charts show the costs to each country, considered one at a time, to staying in the agreement, relative to a strategy of dropping out under the assumption that others continue to abide by the agreement. As already noted, every country in every period shows an economic cost from participating that is less than 5 percent. Thus we have succeeded in meeting the $X=5 \%$ threshold. Figure 9 summarizes the economic costs of participation for each country or region, under the Nash criterion. For each, the first bar shows the present discounted value. For all 12 regions the cost is below 1 per cent. To recall a lesson of Figure $2 b$, the regime could probably survive the defection of MENA (and also TE), but it is much less likely that it could survive the defection of China. For each region the second bar shows the economic loss in whatever period that loss is highest. TE is the highest, almost reaching the threshold value of 5 per cent of income. Next come China and Korea-South AfricaAustralia. The finding that costs are able to stay under the thresholds is gratifying.

\footnotetext{
${ }^{20}$ Viewed from this perspective, places such as India and Africa could sue countries such Saudi Arabia and the United States for the damage that their cumulative past emissions are inflicting on climate-sensitive tropical regions.
} 
Figure 9: Economic losses for each country, by the Nash criterion, compared to $X$ and $Y$ thresholds

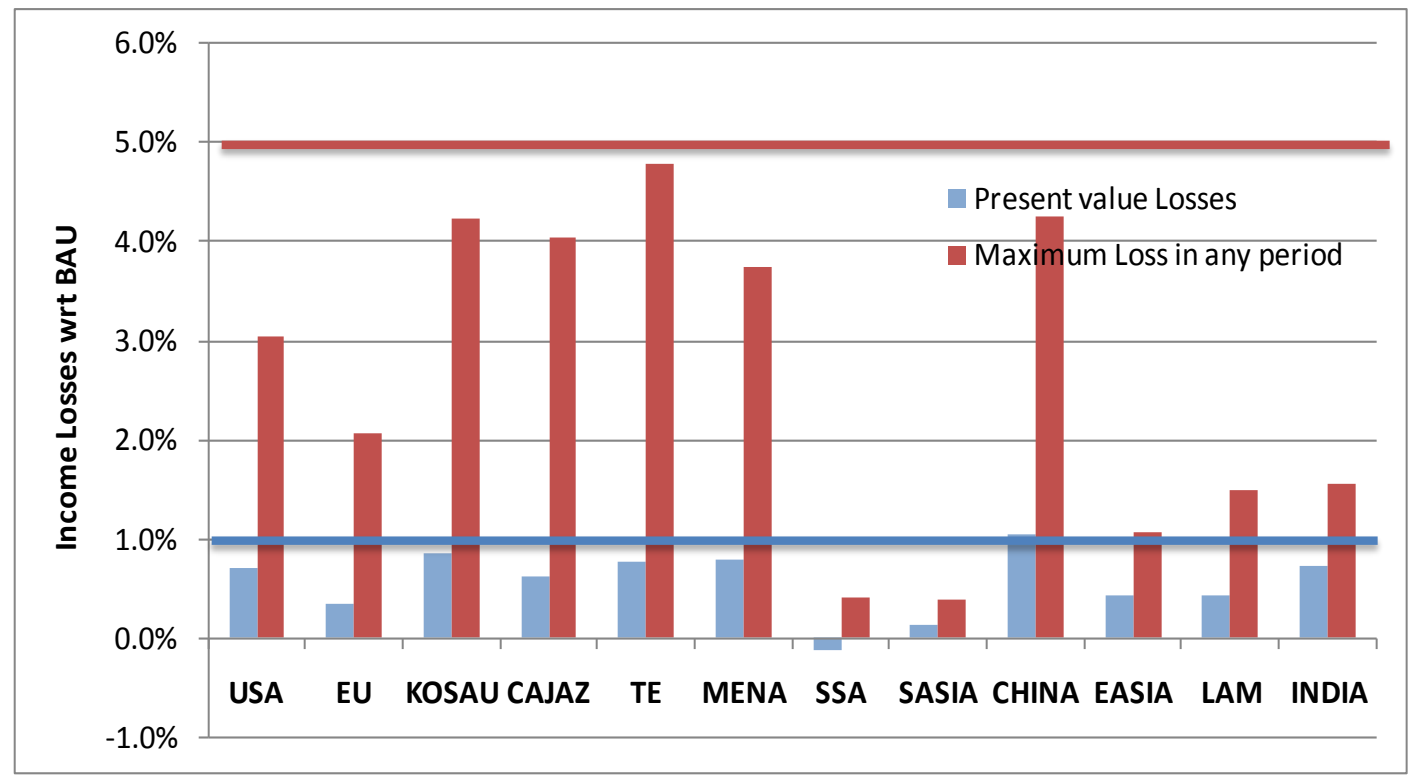

\section{Environmental effects}

Under the emission numbers considered here, the concentration of $\mathrm{CO}_{2}$ in the atmosphere is projected to reach $500 \mathrm{ppm}$ in the late years of the century. Figure 10 shows the path of concentrations. Figure 11 shows the path of temperature, which in 2100 attains a level that is 3 degrees Celsius above pre-industrial levels, as compared to 4 degrees under business as usual. 
Figure 10: Path of concentrations under the 500 ppm CO2 goal

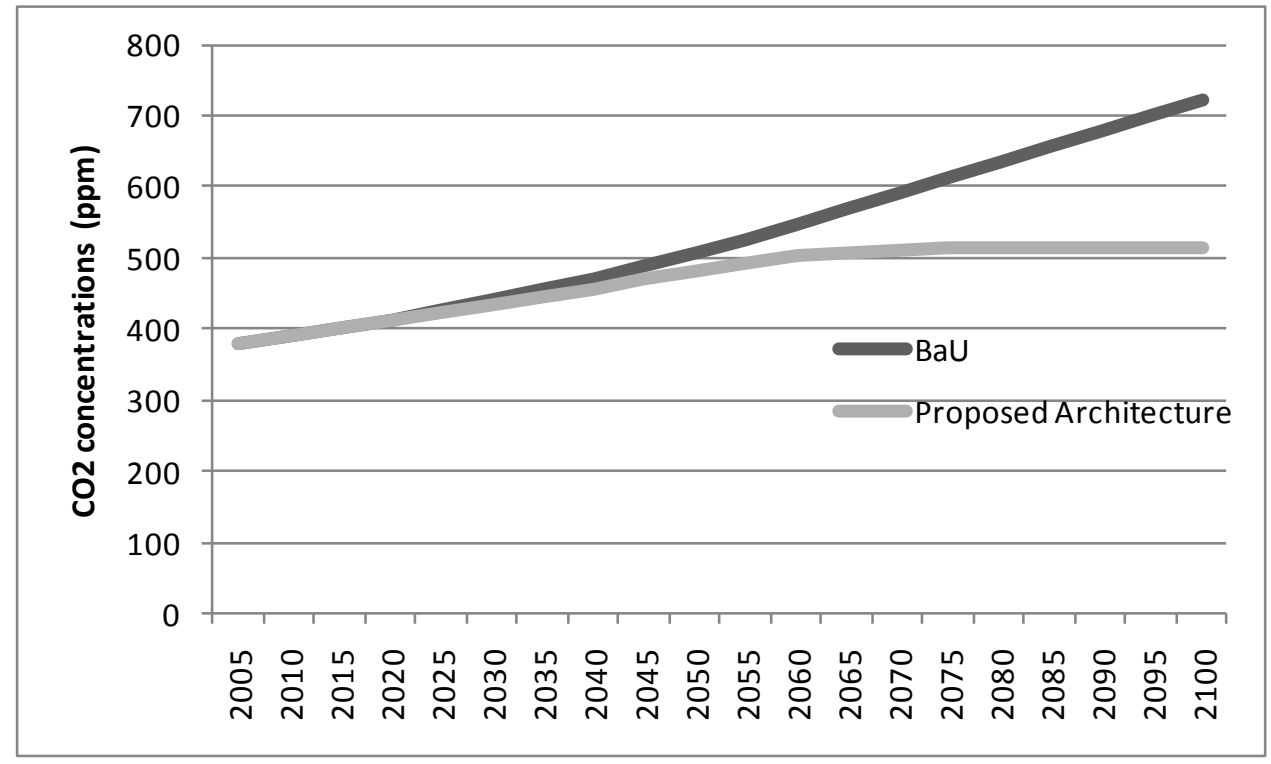

Figure 11: Rise in temperature under the $500 \mathrm{ppm}$ CO2 concentrations goal

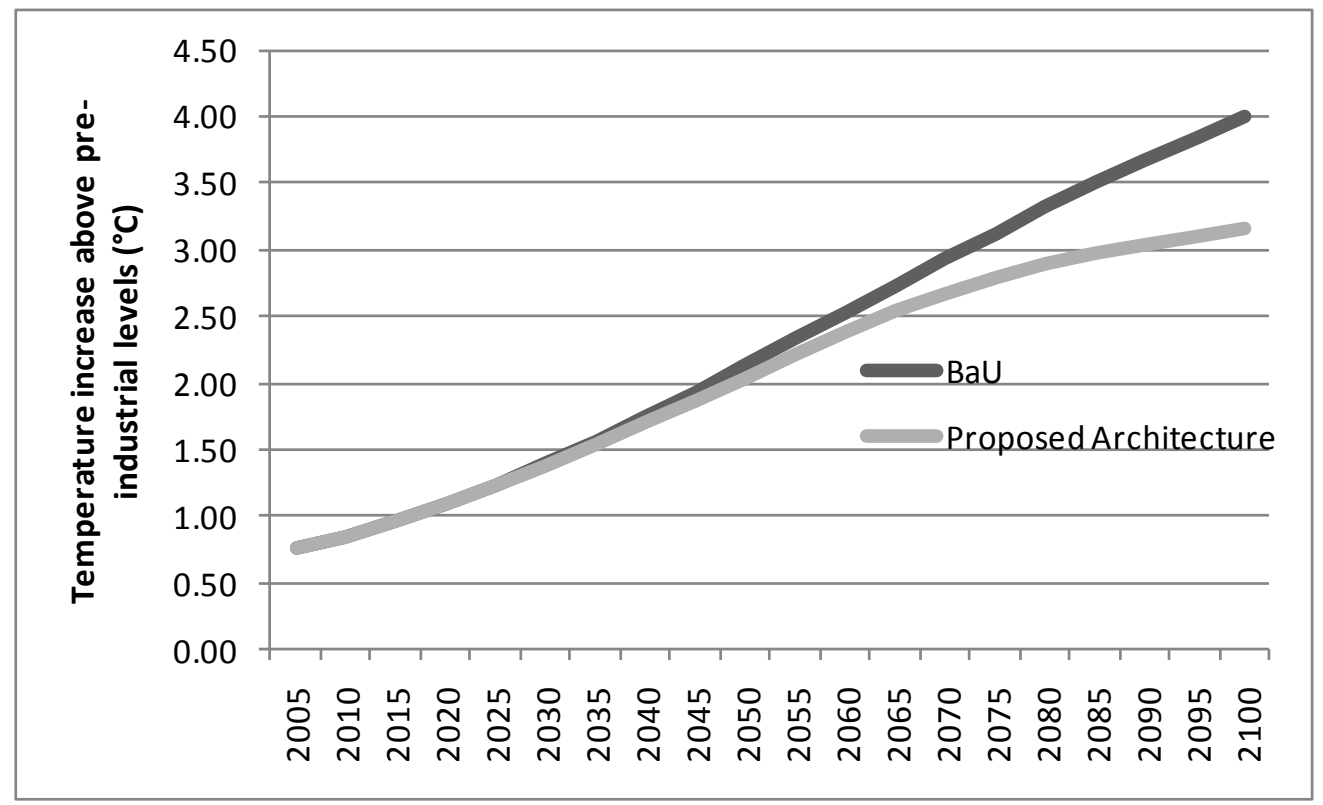




\section{Seeking more ambitious concentration targets: $450 \mathrm{ppm}$ or better}

The concentrations goal that is attained by the emissions path specified above, 500 ppm CO2, is nowhere near sufficient to accomplish the environmental goals that leaders seek. As we have seen, it is estimated to reduce average temperature from a 4 degree increase above pre-industrial levels to 3 degrees. But leaders have supposedly agreed to a target of 2 degrees. We conclude the study by reporting on our most recent explorations of more ambitious environmental goals.

Several of the countries reported more than one possible emissions target under the Copenhagen Accord and Cancun Agreements, in some cases conditioned on what other countries did, as Table 1 reports. The EU, for example, has since 2009 said that it was prepared to achieve a target of emissions 20 per cent below 1990 levels by 2020 if there were no comprehensive international agreement, but 30 per cent below if there was such an agreement. Accordingly we adopt the more aggressive national targets as the starting point for this exercise. Table 5 in Appendix 1 reports these targets for 2020 and 2050, aggregated into the 12 regions that we need for our model. The target here is on all emissions now, including land use emissions and other gasses. We include abatement options in other gasses and avoided deforestation (though not afforestation), consistent with the REDD initiative. As in the previous experiment, the data in the following also include bioenergy with CCS, unless otherwise specified. Other modifications in order to move the targets in a more ambitious direction are reported in Table 5 in Appendix 1.

Figure 12 illustrates the global GHG emissions targets that result from the more ambitious parameter choices. (It and the other graphs described in this section appear in 
Appendix 1.) Emissions of all gases aggregated together do not achieve the Bali objective of halving by 2050 (unless one is measuring relative to BAU). But they do fall to $20 \mathrm{Gt}$ by the end of the century, which is less than half the 2010 level and one fifth the BAU level.

Next, Figure 13 shows the targets for OECD countries. The path of the assigned amounts is not very different from the less ambitious case. Either way, they decline sharply from 2020 to 2050 . The big difference is that actual emissions are substantially lower: by 2035 aggregate emissions have declined below $10 \mathrm{Gt}$, whereas in Figure 3 emissions (of CO2) had barely begun to decline at all. This is because the rich countries now find it far more difficult to buy permits as easily, because the poor countries have fewer to sell. Figure 14 shows the more ambitious targets for developing countries. Assigned amounts now peak as early as 2025. Actual emissions begin to decline from the beginning, as the poor countries sell permits to the rich. But the graph confirms that permit sales are quite small, because assigned amounts are pushed below $30 \mathrm{Gt}$ as early as 2030 , so that there are indeed few extra permits to spare.

The bars in Figure 15 show per capita emissions by each region in each period under the more aggressive targets. Some high emitters like the United States and Australia show targets that are already by 2015 about 1 ton lower per capita than in the 450ppm case. China peaks at 2 tons per capita in 2020 and India never gets much above $1 / 2$ ton. Convergence toward a common low target toward the end of the century is smoother than before.

Turning to the economic effects of these targets, Figure 16a shows the shadow price of a ton of $\mathrm{CO} 2$ rising almost to $\$ 500$ a ton and the price of a gallon of gas rising 
almost to $\$ 4.5$ a gallon, respectively - twice as high as when the environmental goal was less ambitious (Figure 6).

Figure $16 \mathrm{~b}$ illustrates the aggregate global costs. The present discounted value now stands at about 2 per cent of income: $1.6 \%$ if BECCS is allowed and $2.1 \%$ if it is not.

Table 6 reports the present discounted value of economic costs for each region where the alternative of dropping out is defined by the BAU criterion. Economic costs are higher for everyone -- three times the costs of the 450ppm goal in the case of TE, Latin America, and China.

Figure 17 summarizes the economic costs of participation for each country or region measured with respect to the no policy baseline. For each, the first bar shows the present discounted value and the second bar shows the economic loss in whatever period that loss is highest. That costs are very high for the oil producing countries is perhaps not ultimately fatal, because we have argued that the regime could probably survive their non-participation. It may be more worrisome that costs for the big three -- the US, China and India - are above the threshold at least in terms of present discounted value (1\%) and, for China, also above the threshold of the highest cost in any single year (5\%).

One way to give perspective to the estimated costs of climate change mitigation is to express them in terms of delay to economic growth. To attain the environmental goal of 500 ppm, global income at the end of the century is two years behind what it would be under BAU. To attain 440 ppm, income in 2100 is four years behind. 
The environmental consequences of the more aggressive emissions path are also shown in Appendix 1. Figure 18b continues to report concentrations in terms of carbon dioxide alone, for purposes of comparison with the preceding results. Concentrations toward the end of the century level off below 450ppm of $\mathrm{CO} 2$, as compared to $500 \mathrm{ppm}$ and rising in the less aggressive case, or shooting through 700 ppm under BAU. Now that we are including other modes of mitigation, Figure 18a reports concentrations in terms of all greenhouse gases. Mitigation is seen to cut total emissions by almost half (from a BAU level that measures almost 1000 ppm in GHGs). Finally, Figure 19 reports the effect on temperature, which is now substantial: the rise above pre-industrial levels is only 2.3 degrees Celsius, as opposed to about 3 in the less aggressive case or 4 in BAU (or as compared to about 1 degree so far, as of 2011).

\section{Concluding perspective}

Section 7 put the estimated global cost of attaining an environmental outcome corresponding to 2.3 degrees centigrade of global warming at about 2 per cent of income under our formulas approach. One might wonder whether these estimated costs of mitigation are justified by estimates of the avoided costs of environmental damage.

Some economists attempt full cost-benefit analysis, to weigh economic costs of climate change mitigation against estimates of the monetized benefits of climate change mitigation, by means of integrated assessment models. Typical estimates of the monetized costs of a concentrations path corresponding to a 4 degree increase in year2100 temperature (the BAU estimate), as compared to limiting the warming to 2 degrees, 
are between 1 and 4 per cent of aggregate global income. ${ }^{21}$ This range, wide as it is, by no means spans the range of estimates by reputable economists. ${ }^{22}$ Furthermore, many impacts that might be associated with climate change have not yet been estimated. The debate on how to evaluate the impact of extreme events is wide open. Thus the mitigation scenarios studied here could be either far too mild or far too aggressive. The wide range of the damage estimates is one reason why we prefer to leave it to society to make the tradeoff between economic cost and environmental damage and do not attempt to do so ourselves. Our focus is, rather, on how to design a framework under which cooperation is as sustainable as possible, for any given level of environmental ambition.

Some readers, especially those not familiar with the economic models of climate change policy, may be surprised at the high estimated economic costs for hitting what seem like moderate environmental goals. They can rest assured that the cost estimates of the WITCH model allow for dynamic technology effects (hence "Induced Technical Change" in the name) and tend to lie in the middle of the pack of leading economic models (for example the 11 models compared in Clarke, et al, 2009). ${ }^{23}$

\footnotetext{
${ }^{21}$ At the lower end of this range, the $1 \%$ of income estimate comes from Tol $(2002 \mathrm{a}, \mathrm{b})$. He estimates the costs (monetized damages) of 4 degrees of global warming at approximately $1 \%$ of income if national costs are aggregated directly and $1 \frac{1}{2} \%$ if they are aggregated by population under an equity argument, as compared to costs of 2 degrees warming equal to 0 or $1 / 2 \%$ of income, respectively. (See also Tol, 2005.) At the higher end of this range, Nordhaus and Boyer (2000) estimate the costs of 4 degrees of global warming at approximately $4 \%$ of income if national damages are aggregated directly and $5 \%$ if they are aggregated by population, as compared to costs of 2 degrees at about $1 \%$ of income aggregated by either method. (See also Nordhaus, 1994, 2008.) ${ }^{22}$ Mendelsohn et al (1998) estimate much lower damages from global warming, as they concentrate on agricultural impacts where adaptation would play a key role. Stern (2007, 2011) estimates much higher damages, attributable, in particular, to the assumption of a low discount rate which gives weight to estimated damages very far into the future ${ }^{23}$ Tavoni and Tol (2010) argue that the standard models may underestimate the economic costs of attaining the target of 2 degrees $C$.
} 
But of course nobody can be sure that the estimates in these models are correct. Uncertainty regarding economic costs of mitigation is probably not as large as uncertainty regarding the avoided costs of environmental damages. Nevertheless, economic costs may turn out to be either higher or lower than estimated in our model. In future research we plan to explore the implications of uncertainty in technology, economic growth, and the environment. A central attraction of putting the formula approach into effect would be that the parameters could readily be adjusted in future budget periods, as more information becomes available. If technological innovations occur that reduce the cost of hitting any given environmental goal, parameters and targets can then be changed accordingly. The success of the international climate regime is much less sensitive to the designer's initial guess as to the appropriate endpoint than it is to whether the designer takes care not to impose unreasonable costs on any critical country, so that the agreement is comprehensive and credible.

\section{References}

Aldy, Joseph, Scott Barrett, and Robert Stavins, 2003, "Thirteen Plus One: A Comparison of Global Climate Architectures," Climate Policy, 3, no. 4, 373-97.

--- Alan Krupnick, Richard Newell, Ian Parry and William Pizer, 2010, "Designing Climate Mitigation Policy," Journal of Economic Literature, 48, no. 4, December, pp. 903-934.

--- and Jeffrey Frankel, 2004, "Designing a Regime of Emission Commitments for Developing Countries that is Cost-Effective and Equitable," G20 Leaders and Climate Change, Council on Foreign Relations.

--- , Peter Orszag, and Joseph Stiglitz, 2001, "Climate Change: An Agenda for Global Collective Action." The Pew Center Workshop on the Timing of Climate Change Policies. October.

--- and Robert Stavins, 2008, "Climate Policy Architectures for the Post-Kyoto World,"

Environment (Taylor and Francis). Vol. 50, no.3, pp.6-17. 
Baer, Paul, Tom Athanasiou, Sivan Kartha and Eric Kemp-Benedict, 2008, The Greenhouse Development Rights Framework: The Right to Development in a Climate Constrained World (Hendrich Boll Stiftung, Stockholm, $2^{\text {nd }}$ edition).

Barrett, Scott, 2006, "Climate Treaties and 'Breakthrough' Technologies," American Economic Review, vol. 96, no. 2, May, 22-25.

Barrett, Scott, and Robert Stavins, 2003, "Increasing Participation and Compliance in International Climate Change Agreements," International Environmental Agreements: Politics, Law and Economics Vol.3, no. 4, 349-376.

Bierman, Frank, Philipp Pattberg, and Fariborz Zelli, 2010, editors, Global Climate Governance Beyond 2012: Architecture, Agency and Adaptation (Cambridge Univ. Press, Cambridge UK).

Birdsall, Nancy, Dan Hammer, Arvind Subramanian and Kevin Ummel, 2009, "Energy Needs and Efficiency, Not Emissions: Re-framing the Climate Change Narrative," Center for Global Development Working Paper 187 (Washington DC).

Bosetti, V., C. Carraro, M. Galeotti, E. Massetti and M. Tavoni, 2006, "WITCH: A World Induced Technical Change Hybrid Model.” The Energy Journal, pp. 13-38.

---, C. Carraro, A. Sgobbi, and M. Tavoni, 2009, "Modelling Economic Impacts of Alternative International Climate Policy Architectures: A Quantitative and Comparative Assessment of Architectures for Agreement," in Joseph Aldy and Robert Stavins, eds., Post-Kyoto International Climate Policy. (Cambridge, UK: Cambridge University Press).

--- E. De Cian, A. Sgobbi, M. Tavoni, 2009b, "The 2008 WITCH Model: New Model Features and Baseline," Working paper no. 85 (Fondazione Eni Enrico Mattei: Milan).

--- and J. Frankel, 2012, "Politically Feasible Emission Target Formulas to Attain 460 ppm CO2 Concentrations," Review of Environmental Economics and Policy, vol.6, no.1, winter: 86-109. HKS RWP 11-016. Revised from "Global Climate Policy Architecture and Political Feasibility: Specific Formulas and Emission Targets to Attain 460PPM CO2 Concentrations," NBER WP 15516; HPICA Discussion Paper No.09-30; FEEM WP 92, 2009; EMCCC RP 73, 2009.

--- , E. Massetti and M. Tavoni, 2007, "The WITCH Model. Structure, Baseline, Solutions," FEEM Working Paper no. 10.

Cao, Jing, 2009, "Reconciling Human Development and Climate Protection: Perspectives from Developing Countries on Post-2012 International Climate Change Policy," in Post-Kyoto International Climate Policy, edited by Joe Aldy and Rob Stavins (Cambridge University Press: Cambridge, UK).

Chakravarty, Shoibal; Ananth Chikkatur, Heleen de Coninck, Stephen Pacala, Robert Socolow and Massimo Tavoni, 2009, "Sharing Global $\mathrm{CO}_{2}$ Emission Reductions Among One Billion High Emitters," Proceedings of the National Academy of Sciences, early edition. 
Clarke, Leon, Jae Edmonds, Volker Krey, Richard Richels, Steven Rose, Massimo Tavoni, 2009, "International climate policy architectures: Overview of the EMF 22 International Scenarios," Energy Economics 31, S64-S81.

Edmonds, J.A., H.M. Pitcher, D. Barns, R. Baron, and M.A. Wise, 1992, "Modeling Future Greenhouse Gas Emissions: The Second Generation Model," in Modeling Global Climate Change, Lawrence Klein and Fu-chen Lo, editors (United Nations University Press: Tokyo), pp. 295-340.

--- S.H. Kim, C.N.McCracken, R.D. Sands, and M.A. Wise, 1997, "Return to 1990: The Cost of Mitigating United States Carbon Emission in the Post-2000 Period," October ( Pacific Northwest National Laboratory).

Ellerman, Denny, and Barbara Buchner, 2008, "Over-Allocation or Abatement? A Prelminary Analysis of the EU ETS Based on the 2005-06 Emissions Data," Environmental and Resource Economics 41, no. 2, October, pp. 267-287.

Frankel, Jeffrey, 1999, "Greenhouse Gas Emissions," Policy Brief no.52, Brookings Institution, Washington, DC.

--- 2005, "You're Getting Warmer: The Most Feasible Path for Addressing Global Climate Change Does Run Through Kyoto," Trade and Environment: Theory and Policy in the Context of EU Enlargement and Transition Economies, J.Maxwell and R.Reuveny, eds.(Edward Elgar, UK).

--- 2007, "Formulas for Quantitative Emission Targets," in Architectures for Agreement: Addressing Global Climate Change in the Post Kyoto World, J.Aldy and R. Stavins, eds. (Cambridge University Press).

--- , 2009, "An Elaborated Proposal For Global Climate Policy Architecture: Specific Formulas and Emission Targets for All Countries in All Decades," in Post-Kyoto International Climate Policy, edited by Joe Aldy and Rob Stavins (Cambridge University Press). NBER WP 18476.

German Advisory Council on Global Change, 2009, SOlvign the Climate Dilemma: The Budget Approach," (WBGU: Berlin).

Hammett, James, 1999, "Evaluation Endpoints and Climate Policy: Atmospheric Stabilization, Benefit-Cost Analysis, and Near-Term Greenhouse Gas Emissions,"Climatic Change 41: 447-68.

Helm, Dieter, Cameron Hepburn, and Richard Nash, 2003, "Credible Carbon Policy," Oxford Review of Economic Policy 19, no. 3, 438-450.

Llavador, Humberto, John Roemer and Joaquim Silvestre, 2011, "Sustainability in the Presence of Global Warming: Theory and Empirics," prepared for the United Nations Development Program.

Lutter, Randy, 2000, "Developing Countries' Greenhouse Emissions: Uncertainty and Implications for Participation in the Kyoto Protocol,” Energy Journal 21(4): 93-120.

Manne, Alan, Robert Mendelsohn, Richard Richels, 1995, "MERGE: A Model for Evaluating Regional and Global Effects of GHG Reduction Policies," Energy Policy 23:17. 
--- and Richard Richels, 1996, "The Berlin Mandate: The costs of meeting post-2000 targets and timetables," Energy PolicyVol.24, Issue 3, March, pp. 205-210

--- and ---, 1997, "On Stabilizing CO2 Concentrations - Cost-Effective Emission Reduction Strategies," Stanford University and Electric Power Research Institute, April.

McKibbin, Warwick, and Peter Wilcoxen, 2007, "A Credible Foundation for Long Term International Cooperation on Climate Change," in Architectures for Agreement: Addressing Global Climate Change in the Post-Kyoto World, edited by Joseph Aldy and Robert Stavins, (Cambridge University Press).

Mendelsohn, R.O., W.N. Morrison, M.E. Schlesinger and N.G. Andronova (1998), "CountrySpecific Market Impacts of Climate Change," Climatic Change, Vol.45, Nos.3-4.

Nordhaus, William D., 1994, Managing the Global Commons: The Economics of Climate Change (MIT Press: Cambridge).

--- 2006, "Life After Kyoto: Alternative Approaches Global Warming Policies," American Economic Review, Papers and Proceedings, vol. 96, no. 2, May: 31-34.

--- 2008, A Question of Balance: Weighing the Options on Global Warming Policies (Yale University Press).

---. and J.G. Boyer, 2000, "Warming the World: the Economics of the Greenhouse Effect", MIT

Press, Cambridge, Massachusetts.

Olmstead, Sheila, and Robert Stavins, 2006, "An International Policy Architecture for the PostKyoto Era," American Economic Review, Papers and Proceedings, vol. 96, no. 2, May: 35-38.

Pizer, William, 2006, "The Evolution of a Global Climate Change Agreement," American Economic Review, Papers and Proceedings, vol.96, no.2, May, 26-30.

Seidman, Laurence, and Kenneth Lewis, 2009, "Compensations and Contributions under an International Carbon Treaty," Journal of Policy Modeling, 31: 341-350.

Stern, Nicholas, 2007, The Economics of Climate Change: The Stern Review, Cambridge University Press, Cambridge.

---, 2011, “Key Elements of a Global Deal on Climate Change,” London School of Economics.

Stewart, Richard, and Jonathan Weiner, 2003, Reconstructing Climate Policy: Beyond Kyoto (American Enterprise Institute Press, Washington DC).

Tavoni, Massimo, and Richard Tol, 2010, "Counting Only the Hits: The Risk of Underestimating the Costs of Stringent Climate Policies," Climatic Change 100:769-778. 
Tol, Richard S.J., 1998, “The Optimal Timing of Greenhouse Gas Emission Abatement, Individual Rationality and Intergenerational Equity" Fondazione Eni Enrico Mattei Working Paper No. 3.98, Jan.

---, 2002, "Estimates of the Damage Costs of Climate Change - Part I: Benchmark Estimates", Environmental and Resource Economics, Vol. 21.

---, 2002a, "Estimates of the Damage Costs of Climate Change - Part II: Dynamic Estimates," Environmental and Resource Economics, Vol. 21.

---, 2005, “The Marginal Damage Costs of Carbon Dioxide Emissions: An Assessment of Uncertainties," Energy Policy, No. 33.

Victor, David, 2004, Climate Change: Debating America's Policy Options (Council on Foreign Relations, New York).

Wagner, Gernot, James Wang, Stanislas de Margerie and Daniel Dudek, 2008, "The CLEAR Path: How to Ensure that if Developing Nations Adopt Carbon Limits, Their Early Actions Will be Rewarded," Environmental Defense Fund Working Paper, October 30.

Weyant, John, 2001, "Economic Models: How They Work \& Why Their Results Differ." In Climate Change: Science, Strategies, \& Solutions. Eileen Claussen, Vicki Arroyo Cochran, and Debra Davis, editors (Brill Academic Press, Leiden), pp. 193-208.

Wigley, Tom, Rich Richels and Jae Edmonds, 2007, "Overshoot Pathways to CO2 Stabilization in Multi-Gas Context," in Human-induced climate change: An interdisciplinary assessment edited by M.E. Schlesinger (Cambridge University Press), pp. 387-401.

Zhang, Yongsheng, 2008, “An Analytical Framework and Proposal to Succeed Kyoto Protocol: A Chinese Perspective," Development Research Center of the State Council, China, Dec. 